\title{
Redistribución espacial y migración interna de la población en Chile en los últimos 35 años (1965-2002): una síntesis de las hipótesis y la evidencia
}

\author{
Daniela González Ollino* \\ Jorge Rodríguez Vignoli**
}

En el análisis de las tendencias de la distribución espacial de la población y las corrientes migratorias, tres asuntos se contrastan con la evidencia producida mediante el procesamiento de los microdatos de los tres últimos censos chilenos de población y vivienda (1982, 1992 y 2002). El primero atañe a la concentración de la población chilena en el Área Metropolitana del Gran Santiago (AMGS) y en la región político administrativa que la contiene (Región Metropolitana o RM); dos hipótesis en pugna se confrontan con los datos: la que sugiere la prevalencia del atractivo migratorio del AMGS y la RM, como resultado de su capacidad para seguir liderando el dinamismo económico, y la que plantea un cambio de orientación de los flujos, tras lo cual quedarían el AMGS y la RM con saldos negativos por la pérdida que tendrían en el intercambio con las regiones más dinámicas, que serían aquellas mejor ubicadas en la globalización productiva. Los datos sugieren que efectivamente en la segunda mitad del decenio de 1990 la Región Metropolitana y el AMGS mostraron la novedosa condición de zonas de emigración neta, pero que paradójicamente esto no alcanza para revertir el incremento de la concentración de la población nacional en ellas por el efecto combinado de un crecimiento natural sobre la media y una fuerte absorción de inmigrantes internacionales. El segundo asunto refiere a los procesos de convergencia regional y al papel de la migración en ellos, respecto del cual hay varias hipótesis, tanto sobre la existencia de tal proceso en las diferentes dimensiones socioeconómicas, como sobre el efecto de los flujos de migración interna en él.

El impacto de la migración sobre los niveles de escolaridad regional se evalúa usando procedimientos novedosos que operan con microdatos censales -y que se presentan para su discusión-; los resultados indican que en los dos últimos periodos censales la migración entre regiones ha favorecido, aunque muy ligeramente, la convergencia de niveles educativos regionales. Finalmente, el tercer asunto se relaciona con la segregación urbana, respecto de la cual se discute la hipótesis de una reducción de sus niveles y una remodelación de sus formas como resultado del desplazamiento de algunas familias de altos ingresos a comunas periféricas y pobres del AMGS. La evidencia producida y analizada indica que la migración intrametropolitana desempeña un doble papel, pues mientras reduce la escala de la segregación sigue siendo una fuerza que tiende a ensan-

* Asistente de investigación, Celade, División de Población de la Comisión Económica para América Latina y Caribe (CEPAL) de las Naciones Unidas. Correo electrónico: daniela.gonzalez@cepal.org.

** Asistente de investigación, Celade, División de Población de la Comisión Económica para América Latina y Caribe (CEPAL) de las Naciones Unidas. Correo electrónico: jorge.rodriguez@cepal.org.

ESTUDIOS DEMOGRÁFICOS Y URBANOS, VOL. 21, NÚM. 2 (62), PP. 369-406 
char las disparidades socioeconómicas entre comunas. Se concluye que tanto para promover los flujos migratorios afines a la estrategia de desarrollo regional, como para evitar que se consoliden territorios de pobreza dura en las ciudades, donde ésta tiende casi inexorablemente a reproducirse, se requieren políticas territoriales, algunas para reforzar tendencias derivadas de la acción de los mercados y otras, en cambio, para mitigar o contrarrestar tendencias derivadas del libre juego de la oferta y la demanda.

Palabras clave: migración interna, distribución espacial de la población, metropolización, segregación residencial, desplazamientos intrametropolitanos, políticas de población y territorio.

Fecha de recepción: 12 de abril de 2005.

Fecha de aceptación: 8 de julio de 2005.

\section{Spatial Redistribution and Internal Migration of the Population in Chile Over the Past 35 Years (1965-2002): A Summary of the Hypotheses and Evidence}

In the analysis of the trends in the population's spatial distribution and migratory flows, three issues contrast with the evidence yielded by the microdata processing of the last three housing and population censuses in Chile (1982, 1992 and 2002). The first concerns the concentration of the Chilean population in the Metropolitan Area of Greater Santiago (MAGS), and the political and administrative region in which it is located (Metropolitan Region or RM). Two competing hypothesis are compared with the data, one suggesting the prevalence of the migratory attraction of MAGS and RM, as a result of their capacity to continue leading economic dynamism and the other proposing a change of orientation of the flows, after which MAGS and RM would end up with a negative balance because of the loss they would experience in the exchange with more dynamic regions, which would be better positioned within globalized production. The data suggest that during the second half of the 1990s, the Metropolitan Region and MAGS began to act as areas of net emigration, but that paradoxically, this failed to revert the increase in the concentration of the national population in them, due to the combined effect of overaverage natural growth and the high absorption of international immigrants. The second issue refers to the processes of regional convergence and the role of migration in them, about which there are several hypotheses, concerning both the existence of this process in various socio-economic dimensions and the effect of internal migration flows in it.

The impact of migration on the regional educational attainment levels is evaluated using novel procedures that operate with census microdata-and which are submitted for discussion. The results indicate that during the past two census periods, migration between regions has favored-albeit only slightly- the convergence of regional educational attainment. Finally, the third issue is relative to urban segregation, a propos of which the author discusses the hypothesis of a reduction of its levels and a remodeling of its forms as a result of the displacement of certain high-income families to peripheral, poor communes in MAGS. The evidence produced and analyzed indicates that intra-metro- 
politan migration plays a dual role, since while it reduces the scale of segregation, it continues to be a force that tends to increase the socio-economic gaps between communes. The authors conclude by saying that in order to promote migratory flows in keeping with the regional development strategy, and prevent the consolidation of areas of entrenched poverty in the cities, where it invariably tends to be reproduced, territorial policies are required, to reinforce tendencies derived from the actions of markets and to offset the trends derived from the unrestricted effects of supply and demand.

Key words: internal migration, spatial distribution of the population, metropolitanization, residential segregation, intra-metropolitan displacement, population and territorial policies.

\section{Los asuntos, las hipótesis, los argumentos y los vacíos de investigación}

La concentración metropolitana y la dinámica de las regiones

El futuro del patrón de distribución geográfica de la población en los países está en discusión debido a los impactos territoriales provocados por las transformaciones productivas y sociales acaecidas desde el decenio de 1970. La apertura económica y la contracción del empleo público erosionaron las bases de sustentación de los espacios que albergaban a la industria sustitutiva de importaciones y al empleo estatal, que solían ser áreas metropolitanas. Por otra parte, el sostenido incremento del intercambio financiero, comercial, cultural y simbólico en el orbe, así como la expansión de la interacción y el control a distancia en tiempo real gracias a las redes de comunicación mundiales, procesos que en su conjunto constituyen la globalización, impusieron nuevas condiciones de competencia entre los países, y también entre las regiones y localidades dentro de aquéllos. Por diferentes razones -como la masa crítica de recursos humanos calificados, las economías y sinergias de aglomeración, las ventajas comparativas naturales, el liderazgo y visión de los gobernantes, las políticas públicas exitosas y las fortalezas institucionales-, algunas regiones han logrado insertarse dinámicamente en el mercado mundial, pero otras han quedado atrás (Rodríguez, 2002; Benko y Lipiez, 2000; Caravaca, 1998).

En el caso de Chile, varios autores han sugerido que hay regiones "ganadoras" y "perdedoras" como resultado de tales cambios (Daher, 2002, 1998 y 1994). La idea básica -con matices entre los autores y 
acentos según el periodo que se considere- es que la profunda inserción del país en la economía mundial ${ }^{1}$ basada en la explotación de materias primas $^{2}$ ha fortalecido la posición de algunas regiones históricamente postergadas, ya que en los últimos años consolidaron su producción primaria para exportación ${ }^{3}$ y, en cambio, ha debilitado a las tres regiones donde solían concentrarse las actividades secundarias y del sector público (Metropolitana, Valparaíso y Bío-Bío. Para una imagen de la regionalización chilena véase el mapa 1 ).

En contraposición con esta hipótesis, otros autores han planteado la continuidad del patrón de localización concentrado en la RM, y en el AMGS ${ }^{4}$ en particular, como resultado de la plasticidad mostrada por ambas regiones ante el embate de situaciones adversas, y de su capacidad para reposicionarse mediante diversos mecanismos (De Mattos, 1999). Algunos de estos mecanismos constituyen una aportación al desarrollo nacional, pues resultan de un aumento de la productividad de procesos de reconversión productiva basados en sus ventajas comparativas (recursos humanos calificados, tecnología, conectividad física, comunicacional, simbólica y virtual, cooperación y sinergias interempresariales, etc.). Otros son consustanciales a la lógica jerárquica del proceso productivo que persiste más allá de los cambios de la estructura económica; se trata de las tareas de control, comando, supervisión y representación simbólica, que siguen recayendo en las regiones más poderosas. Finalmente, también están algunos mecanismos que no siempre contribuyen al bienestar agregado y que se basan en la pertinaz capacidad de las regiones centrales de imponer sus condiciones y sacar partido del dinamismo de las restantes mediante reglas de tributación que las benefician, y también porque concentran las inversiones públicas y albergan los espacios donde se adoptan las decisiones relevantes para el país (De Mattos, 1999). Por cierto, ninguno de los investigadores que plantean esta hipótesis niega las fuerzas de redistribución territorial que se han desencadenado en Chile en las últimas tres décadas; sin embargo rechazan la posibilidad de una alteración

${ }^{1}$ En 2004, las exportaciones superaron los 30000 millones de dólares y representaron más de un tercio del PIB.

${ }^{2}$ Algunas de ellas tradicionales (como la minera), otras emergentes (como la silvicultura, la fruticultura y la piscicultura), y unas pocas terciarias, como el turismo, las telecomunicaciones, los servicios financieros, y algunos bienes manufacturados.

${ }^{3}$ A causa de lo cual Daher las denomina "regiones commodities" (Daher, 2003).

${ }^{4}$ Integrado por 32 comunas de la Provincia de Santiago más las comunas de San Bernardo en la Provincia de Maipo y Puente Alto en la Provincia Cordillera. Para más detalles véase la base de datos del proyecto Distribución Espacial y Urbanización de la Población en América Latina y el Caribe (DEPUALC) (Celade-CEPAL, 2005). 


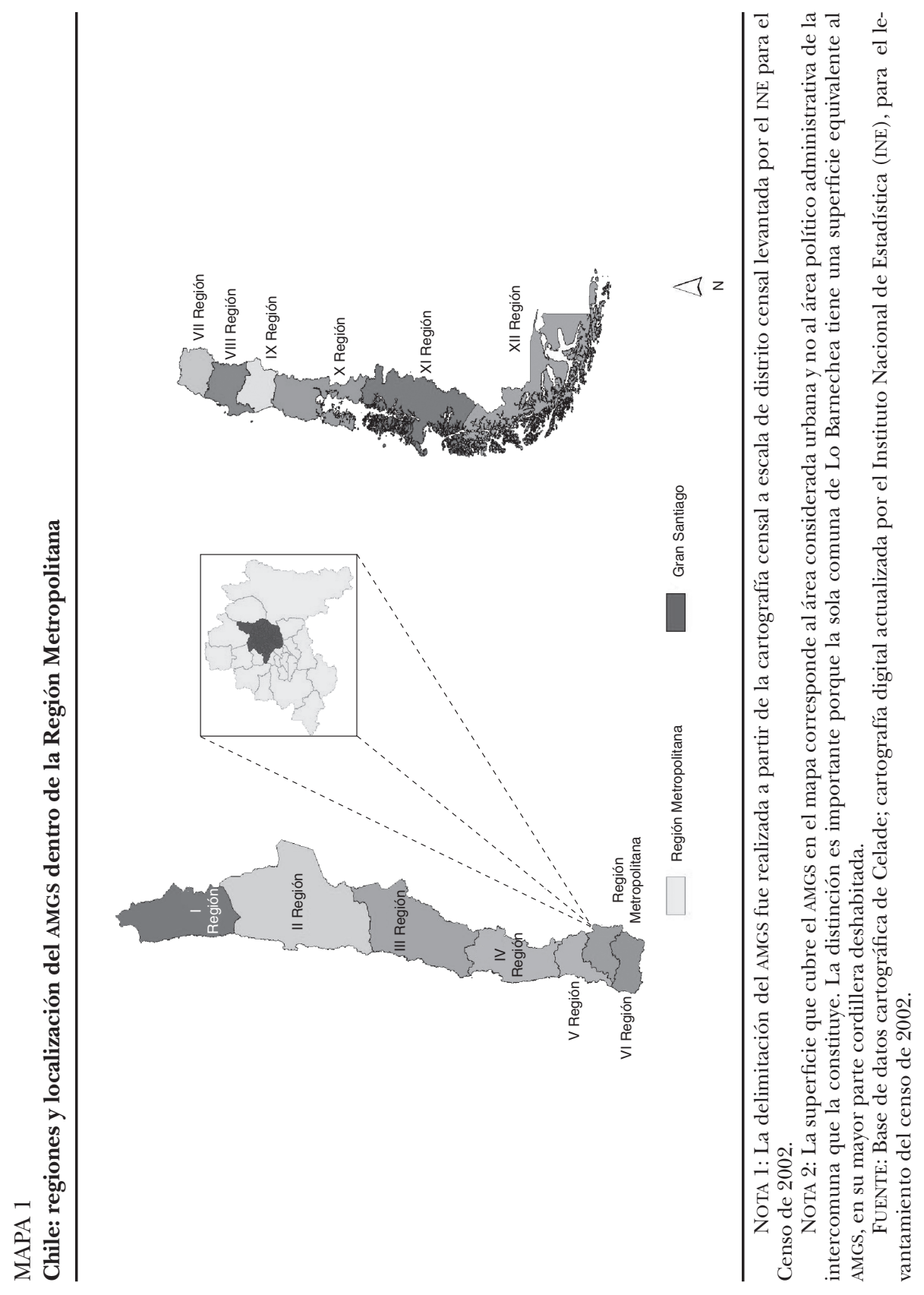


sustancial y sustentable del patrón de concentración de las actividades económicas.

La evidencia disponible no permite zanjar la discusión, pues simultáneamente ocurren flujos de inversión y bonanza productiva en las regiones exportadoras (Daher, 2002) y la persistente gravitación económica de la Región Metropolitana (De Mattos, 1999). Algunos ejercicios empíricos efectuados para clasificar las regiones según su dinamismo económico y conforme a ello atribuirles la condición de "ganadora" o "perdedora" durante la década de 1990 concluyen que entre las ganadoras estarían algunas exportadoras (principalmente las vinculadas a la producción minera en el norte) y la metropolitana (Silva, 2003). Hacia fines de 2004 parecía haber cierto consenso entre ambas posiciones: se reconocía que la Región Metropolitana tiene su espacio propio y, sobre todo, una capacidad sobresaliente de ajuste y de protección frente a las crisis, pero como contrapartida se aceptaba que las regiones motrices de la economía tendían a ser las exportadoras.

Ahora bien, tales discusiones e investigaciones virtualmente no examinan las tendencias migratorias; en general su consideración de los aspectos demográficos no va más allá de la evolución del peso de cada región dentro de la población chilena. Esto último marca una diferencia respecto de las investigaciones sobre las tendencias metropolitanas concentradoras o desconcentradoras en otros países de la región, donde se analizan cuidadosamente los flujos migratorios (Rodríguez, 2004 y 2002; Izazola, 2004; Pinto da Cunha, 2002). Es necesario, entonces, actualizar el conocimiento sobre el atractivo migratorio de la RM y el AMGS, y precisamente ése es uno de los objetivos de este documento.

\section{La convergencia regional}

El debate sobre la convergencia tuvo un auge durante los últimos 15 años del siglo Xx cuando dos escuelas de pensamiento económico plantearon la posibilidad de que este fenómeno pudiese dirimir la disputa respecto de las fuentes fundamentales del crecimiento económico. Aunque originalmente la discusión refería a la convergencia económica entre países, ${ }^{5}$ rápidamente se pasó a examinar la conver-

${ }^{5}$ Los teóricos del crecimiento endógeno, que introducían el progreso técnico en sus modelos y que descartaban la tesis de los rendimientos decrecientes del capital, proponían un futuro de no confluencia, contrario al que se desprendía lógicamente del modelo neoclásico con rendimientos decrecientes del capital. 
gencia entre las regiones que formaban los países. Finalmente los resultados empíricos no zanjaron la disputa teórica y el debate tendió a desvanecerse cuando los teóricos neoclásicos descartaron que la convergencia económica, en sus diferentes modalidades, entre países o entre regiones dentro de los mismos, fuese un corolario de su modelo (Silva, 2003; Cuervo, 2003).

En Chile se han llevado a cabo varios análisis para evaluar la hipótesis de la convergencia (Cuervo, 2003), pero sus resultados tampoco han sido concluyentes. Después de revisar varios estudios empíricos de convergencia económica regional en el país y de usar diferentes herramientas econométricas, entre ellas la inclusión de la dependencia espacial en sus modelos, Aroca y Bosch (2004) concluyen que si bien no se puede rechazar la hipótesis de B-convergencia ${ }^{6}$ incondicional para el periodo 1960-1998, el parámetro de convergencia de 1.2\% revela una velocidad muy lenta del proceso. Más importante aún, sus resultados sugieren que durante el decenio de 1990 hay ausencia de ß-convergencia. Estudios más recientes, que sitúan a Chile como un caso más entre varios de América Latina, ratifican el carácter errático del proceso de convergencia y el hecho de que en los últimos años la tendencia haya sido hacia la divergencia (Silva, 2003: 16). Entre los estudios sobre el tema hay uno que introduce la migración para evaluar su efecto sobre los parámetros de convergencia; utiliza las tasas de migración que se derivan de los censos de 1970, 1982 y 1992, y concluye que los flujos entre regiones atentan contra la convergencia, pues: "al mantener la migración constante [...] la velocidad de convergencia es mayor que cuando ésta varía [...], lo que indica que la migración juega un rol que va en contra de la convergencia” (Fuentes, 1997: 191, citado por Cuervo, 2003: 36).

Ahora bien, pocos estudios se han referido a la convergencia social ${ }^{7}$ regional y al eventual efecto de la migración sobre ella. Las incógnitas que en este plano resultan relevantes para el presente estudio son dos: a) ¿hay una tendencia a la convergencia de los indicadores demográficos de las regiones?; $b$ ) ¿contribuye la migración entre regiones a que los índices sociales tiendan a igualarse, o por el contrario, favorece su

${ }^{6}$ En la literatura especializada se distinguen dos modalidades de convergencia. Una de ellas es la llamada convergencia beta, que se verifica si las economías pobres crecen más que las ricas. La otra es la convergencia sigma, que ocurre si la dispersión de la renta real per cápita entre grupos de economías tiende a reducirse en el tiempo.

${ }^{7}$ En este sentido, algunos de los trabajos sobre convergencia económica regional evalúan la de tipo sigma, la que, por concentrarse en el ingreso medio, resume aspectos sociales. 
distanciamiento? Respecto de esta última interrogante, recientemente se han desarrollado y aplicado con relativo éxito procedimientos que facilitan tener una estimación directa del efecto neto de la migración sobre algunos indicadores sociales en las zonas de origen y de destino (Rodríguez, 2004). Precisamente, la aplicación de estos procedimientos brindará la posibilidad de validar o rechazar la hipótesis de que la migración entre regiones tiene un efecto adverso sobre la convergencia regional de los indicadores sociales.

\section{La segregación residencial}

Hay una preocupación creciente por la segregación residencial, asunto cuya evidencia va ascendiendo en la región tanto para los dirigentes políticos como para los investigadores y la población en general. Respecto de ello hay varias líneas de explicación y de análisis (Flores, 2005; Rodríguez y Arriagada, 2004; Kaztman, 2003 y 2001; Kaztman y Wormald, 2002; Machado, 2001; Rodríguez, 2001; Sabatini, Cáceres y Cerda, 2001; Jargowsky, 1996; Massey, White y Phua, 1996; Schelling, 1978). En este documento sólo se considerarán dos enfoques opuestos: el de las ciudades duales y el de las ciudades fragmentadas. El primero ha sido atribuido a los teóricos de la ciudad global y de la sociedad-red, Manuel Castells ${ }^{8}$ y Saskia Sassen (De Mattos, 2002; Wessel, 2000), y con frecuencia se propone como uno de los vértices de la teoría urbana actual en asociación con otras nociones de creciente peso en el debate sociológico, como exclusión y polarización (Ribeiro y Lago, 1999, en www.ippur.ufrj. br/observatorio/download/espaco_social_metropoles.pdf). Básicamente con la idea de ciudad dual se procura describir la expresión espacial de la contraposición, generada por el cambio tecnológico y la globalización, entre rubros económicos, ocupaciones, y grupos sociales dinámicos y obsolescentes. La reducción de la fricción de distancia, así como la competencia a escala mundial, afectan profundamente a una parte importante de las actividades productivas de las ciudades globales, de ahí que se trasfieran a mejores localizaciones (menos costosas, cerca de mercados emergentes, con esquemas de incentivos favorables, etc.) y dejen desamparados importantes segmentos de trabajadores tradicio-

${ }^{8}$ O sociólogo espanhol Manuel Castells foi um dos primeiros a alertar-nos dos perigos da "cidade dual", sistemas urbanos que podem ser espacial e socialmente polarizados entre grupos bem dotados de serviços (tais como interconexões eletrônicas) e, na outra ponta, grupos desprovidos desses melhoramentos (www.grupoemaus.com.br/formacao/conac/futuro_das_cidades. $\mathrm{htm})$. 
nales. Como contrapartida, el dinamismo de las actividades de control, supervisión y comando, así como de rubros industriales y tecnológicos y de los servicios de apoyo especializado a la producción, a la administración y a la gestión genera un auge para otro grupo importante de trabajadores, en general más calificados y cercanos a los que se ha llamado "analistas simbólicos". Éstos, a su vez, tienen demandas de servicios que atiende una nueva clase baja en buena medida constituida por migrantes de países pobres. En suma, la estructura social se polariza e incluso se dualiza entre un segmento ganador -que es amplio y no se limita a los grandes empresarios, altos ejecutivos o profesionales especializados-, y otro perdedor -principalmente a) pequeños y medianos empresarios y comerciantes incapaces de competir con las grandes empresas y corporaciones; $b$ ) trabajadores manufactureros de mediana y baja calificación cuyos empleos se pierden por la relocalización industrial; y c) empleados de nivel medio y bajo, públicos y privados, cuyos puestos de trabajo se externalizan incluso más allá de las fronteras nacionales-, pero al irrumpir una nueva clase baja "emergente" con la globalización, se introduce una dosis de complejidad y dinamismo a esta primera visión dicotómica relativamente rígida. Es interesante que esta nueva clase baja "emergente" tenga un perfil particular dependiendo del país, pues en algunos casos se trata preferentemente del sector informal, en otros principalmente de la pequeña y mediana empresa, y en los más desarrollados suelan ser trabajadores de servicios personales o externalizados de baja calificación.

Ahora bien, el que se impute a los teóricos de la ciudad global la hipótesis de la dualización es consecuencia de sus planteamientos más bien dispersos, pues no siempre es evidente lo que entienden por dualización metropolitana, y en algunos casos no descartan otras opciones de configuración territorial de las ciudades globales (Wessel, 2000). Tres fundamentos han sido usados para esta imputación en la que de una hipótesis relativa al mercado de trabajo se pasa a una relativa a la localización de la fuerza de trabajo y de la población metropolitana en general. El primero es semántico y remite al uso que hace Castells de la expresión ciudad dual:" "as early as 1989 (p. 225), Castells anticipated increasing differentiation of labour and a new urban dualism. With certain reservations, he put forth a fairly strong conclusion: the global city is also the dual city (p. 343)" (Wessel, 2000: 1948). El segundo es conceptual y remite a los planteamientos isomorfistas

${ }^{9}$ Más aún, junto a Mollenkopf, Castells escribió un texto sobre Nueva York que en su título alude a la ciudad dual (Mollenkopf y Castells, 1991). 
de estos autores entre estructura social y espacial: "transformación espacial debe entenderse en el contexto más amplio de la transformación social: el espacio no refleja la sociedad, sino que la expresa, es una dimensión fundamental de la sociedad, inseparable del proceso global de organización y cambio social" (Castells, 2001: 493, citado por De Mattos, 2002). Y el tercero es sustantivo, pues hay un planteamiento específico sobre una tendencia a la partición territorial de estas ciudades:

Structural dualism leads at the same to spatial segregation and to spatial segmentation, to sharp differentiation between the upper level of the information society and the rest of the local residents as well as to endless segmentation and frequent opposition among the many components of restructured and destructured labor" [Castells, 1989: 227, citado por Wessel, 2000: 1949].

El aspecto relativamente nuevo es que los procesos de exclusión social más profundos se manifiestan en una dualidad intrametropolitana, particularmente en las grandes ciudades de casi todos los países, siendo asî que en distintos espacios del mismo sistema metropolitano existen, sin articularse y a veces sin verse, las funciones más valorizadas y las más degradadas, los grupos sociales productores de información y detentadores de riqueza en contraste con los grupos sociales excluidos y las personas en condición de marginación. Dichos procesos existen en casi todas las grandes ciudades, porque su lógica está inscrita en el nuevo modelo de desarrollo tecnoeconómico [Borja y Castells, 1997: 60, citado por De Mattos, 2002].

En suma, aunque la manifestación territorial del dualismo en el mercado de trabajo que se verifica en las ciudades globales nunca fue descrita con precisión por Castells o Sassen, y más recientemente otros autores han considerado que el desmonte del estado de bienestar y de las políticas de regulación urbana son tanto o más importantes que la globalización para explicar la polarización territorial (Wessel, 2000), numerosos investigadores la han traducido literalmente como una polarización en dos partes, con lo cual la segregación se intensificaría y se daría, además, en gran escala, pues una parte de la ciudad está en auge o recuperación (gentrificación) mientras que la otra está precarizada o en decadencia (Kaztman, 2001; Ribeiro y Lago, 1999; Rodríguez y Winchester, 2001).

La hipótesis de las ciudades duales ha sido criticada por diversas razones y desafiada por numerosas investigaciones empíricas (De Ma- 
ttos, 2002; Sabatini, Cáceres y Cerda, 2001; Ribeiro y Lago, 1999; Preteicelle, 1994). Sin entrar en el debate sobre la polarización social vinculada a la nueva economía global, la visión de ciudades segmentadas en dos componentes opuestos (aunque no forzosamente equivalentes en tamaño y extensión) simplifica erradamente la realidad urbana y pierde el mosaico que muchas ciudades tienen como legado histórico o como resultado de una combinación compleja de fuerzas económicas y políticas. Por cierto, a la hipótesis de la ciudad dual no se le opone una de la ciudad integrada o igualitaria que efectivamente chocaría contra la mayor parte de los planteamientos conceptuales y la evidencia disponible; más bien se le opone una de la ciudad fragmentada en la que se entrecruzan sectores económicos y sociales sin que aquello signifique una articulación productiva o una interacción social. Entre los apelativos usados para referirse a esta modalidad de configuración social metropolitana está el de "ciudad fractal" (De Mattos, 2002).

Es interesante que el AMGS históricamente se haya prestado para ser descrita por el enfoque de la ciudad dual, pues es nítida la diferencia entre el oriente, donde vive la elite, y el resto de la ciudad, ocupado en su mayoría por las clases media-baja y baja. Además, el AMGS fue escenario de poderosas y extensas "cirugías urbanas" en el decenio de 1980, como ocurrió con muchas otras ciudades de América Latina. Estas cirugías se llevaron a cabo con una marcada selectividad socioeconómica, procurando que las comunas "acomodadas" del oriente se desprendieran total o casi totalmente de sus "bolsones de pobreza" (Lombardi y Veiga, 1989). Sin embargo, el decenio de 1990 y los primeros años del siglo XXI han estado marcados por tendencias aparentemente contradictorias. Por una parte hay signos que abonan a la hipótesis de la dualización: la encuesta Caracterización Socioeconómica Nacional (Casen) muestra que se mantiene la desigual distribución del ingreso en la capital (consonante con lo que ocurre a escala nacional; para más detalles véase www.mideplan.cl), se acentúan algunas disparidades comunales a causa de las enormes diferencias de las finanzas locales entre municipios ricos y pobres, se refuerza el carácter autárquico de la zona este porque crecientemente se ubican allí servicios y puestos de trabajo, y se consolida el sector oriente como el ámbito selecto y afluente de la capital al extenderse las urbanizaciones de lujo hacia diversos valles precordilleranos. Por otra parte, en cambio, hay indicios de un "derrame" de la elite hacia comunas históricamente pobres pero crecientemente conectadas con el núcleo oriente; más 
aún, se manifiesta un todavía pequeño pero notorio proceso de desplazamiento de familias de la elite hacia ámbitos rurales cercanos a Santiago, que se basa en la conservación del trabajo y la escuela de los niños en la ciudad (y la escuela en el sector oriente de la ciudad). Asimismo, hay signos de que la inversión privada y pública se diversifica territorialmente, y va diseminándose el equipamiento "global" (supermercados, centros de entretención, universidades privadas, etc.) por toda la ciudad (aunque las comunas del oriente siguen concentrando una fracción importante del mismo). Por último, el mejoramiento vial y la ampliación y aumento de las carreteras de alta velocidad (muchas de ellas de paga) modifican de manera radical los tiempos de desplazamiento hacia el centro y el oriente de la ciudad, con lo que se eleva significativamente el interés de ciertos segmentos de la elite (familias con niños) por algunos predios localizados en comunas pobres; esta transformación crucial sugiere que a mediano plazo podría producirse una mutación a gran escala de la localización de la elite, que tendería a dispersarse, al menos parcialmente, por la periferia.

Nos proponemos contribuir a dar respuesta a dos dudas. Una de ellas tiene que ver con las tendencias de la segregación, habida cuenta del debate entre quienes sostienen que está aumentando y quienes plantean lo contrario. La segunda consiste en evaluar el efecto de la migración intrametropolitana sobre las disparidades intercomunales y las modalidades de segregación residencial.

\section{La evidencia}

Hipótesis sobre la concentración metropolitana y la dinámica de las regiones

El cuadro 1 ofrece un argumento para dilucidar primero la disputa sobre la concentración de la población en la Región Metropolitana: en los últimos 30 años la RM aumentó su participación en el total nacional, y en 2002 cuatro de cada 10 chilenos vivían en ella. Es decir, la reorientación de la actividad económica afín con producción asentada fuera de la RM, los grandes flujos de inversión pública y privada hacia regiones distintas de la metropolitana, y los procesos de regionalización y descentralización administrativa llevados a cabo en las últimas tres décadas, no han impedido que la concentración de población en la RM persista e incluso se acentúe. Con todo, la imagen del dinamismo regional tampoco se descarta íntegramente, sobre todo porque las 


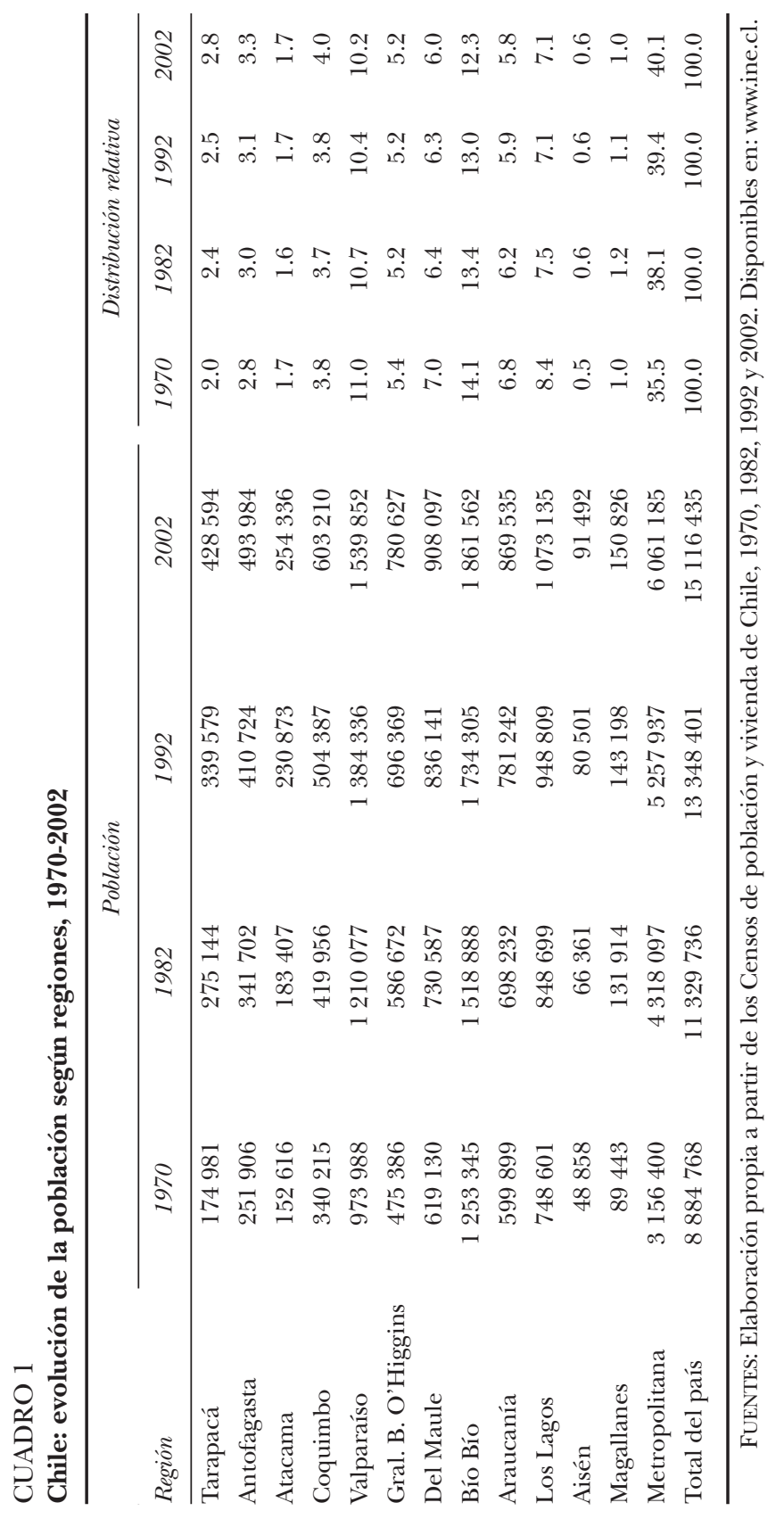


regiones del norte ganan o mantienen representación en sintonía con la expansión de rubros de exportación tradicional (como la minería, en particular la del cobre, ahora ampliada al sector privado) y rubros emergentes (como el turismo, el comercio, y la producción agrícola de alta calidad y buena valoración en los mercados). Es notorio que el centro sur del país pierde representación, revelando un cierto letargo social y económico que tiene raíces históricas -por ejemplo, los altos índices de pobreza en regiones como la de la Araucanía (véase el procesamiento en línea de las encuestas Casen en www.mideplan.cl)-y recientes -en particular los efectos adversos de la apertura comercial sobre la agricultura tradicional, sobre la industria del carbón y sobre los complejos fabriles sustitutivos de importaciones en zonas como Concepción-. En suma, se rechaza la hipótesis de la desconcentración demográfica, aunque los determinantes directos (demográficos) e indirectos (socioeconómicos, políticos) de la tendencia encontrada aún deban ser objeto de indagación detallada. ${ }^{10}$

Ahora bien, la hipótesis de la concentración no refiere, en rigor, a la RM sino al AMGS. No hay duda de que Santiago es una ciudad primada. Los 5.4 millones de habitantes que registró el AMGS en el censo de 2002 significan 36\% de la población nacional y $41 \%$ de la urbana. Con todo, la gráfica 1 ofrece una imagen ambigua de la evolución de la concentración. Si se considera el peso de la ciudad dentro de la población chilena, no hay duda de que el proceso de concentración ha sido sostenido en el tiempo, pues de $23 \%$ en 1952 pasa a $36 \%$ en 2002. Si se considera el índice de primacía de orden tres ${ }^{11}$ se refuerza el planteamiento, porque mientras en 1952 la población del AMGS era 2.4 veces la población sumada de las tres áreas metropolitanas que le seguían en tamaño (a la sazón: Valparaíso, Concepción y La SerenaCoquimbo), en 2002 era de tres veces la suma de la población de Valparaíso, Concepción y Antofagasta. ${ }^{12}$ La imagen cambia si se toman en cuenta otros dos indicadores. Respecto de la población urbana, la representación del AMGS es bastante estable y, de hecho, en las dos últimas décadas ha experimentado un leve descenso; esto significa que el AMGS está creciendo con un poco más de lentitud que el resto urbano. Yel índice de primacía de orden once ${ }^{13}$ definitivamente revela que

${ }^{10}$ Aunque ya hay avances en tal sentido (véase Rodríguez y González, 2004).

${ }^{11} \mathrm{El}$ más usado y que ubica en el numerador a la población de la ciudad principal y en el denominador la suma de la población de las tres ciudades que le siguen en tamaño.

${ }^{12}$ Aun cuando el incremento de este índice se ha moderado desde el decenio de 1980.

${ }^{13}$ También estándar. Coloca en el numerador a la población de la ciudad principal y en el denominador a la población sumada de las 11 ciudades que le siguen en tamaño. 


\section{GRÁFICA 1}

Chile: evolución de indicadores de la concentración de la población en el AMGS, 1952-2002

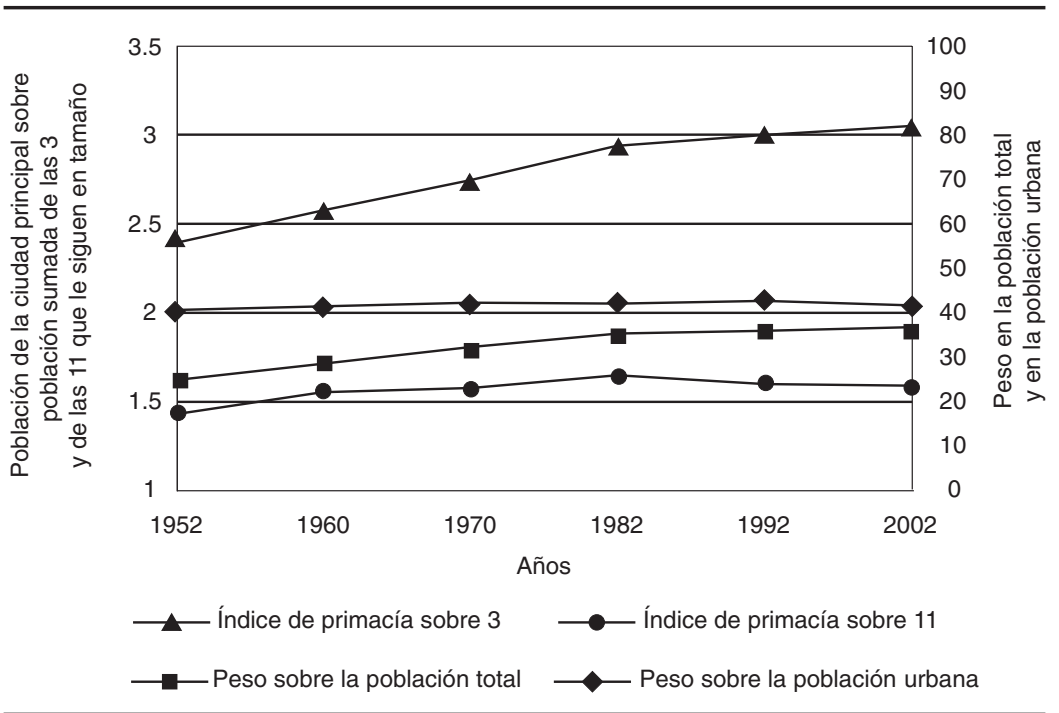

FUENTE: Elaboración propia con datos de la base de datos "Distribución espacial de la población y urbanización en América Latina y el Caribe, DEPUALC" (www.cepal. org/celade).

respecto al resto de las ciudades grandes y medianas de Chile -en 2002 la ciudad clasificada en el decimosegundo lugar por su cantidad de población era Puerto Montt, con 156000 habitantes- el AMGs ha sido menos dinámica desde el decenio de 1980.

En suma, si hubiese que apoyar una hipótesis, la de la desconcentración demográfica de Santiago resulta más favorecida por la evidencia disponible, en particular porque hay claros signos de que la mayoría de las ciudades medias del país son más dinámicas, en términos demográficos, que el AMGs.

Sin embargo, como ya se insinuó (aunque no se profundizó) respecto de la gravitación de la Región Metropolitana, los procesos genuinos de desconcentración no se deducen de los diferenciales del ritmo de crecimiento demográfico, sino más bien de la conservación o pérdida de su atractivo migratorio. Y los indicadores de migración interna entre comunas revelan que entre 1997 y 2002 el AMGS perdió población en su intercambio con el resto del país. Estas cifras no tienen 
precedentes históricos y sugieren una erosión del atractivo del AMGS frente a un creciente vigor de otros centros urbanos. Ahora bien, ¿no será que esos nodos alternativos son ciudades cercanas al AMGS, de manera tal que más que una desconcentración genuina de la capital se esté verificando un proceso de metropolización difusa o la constitución de una gran metrópoli extendida? El cuadro 2 contribuye a dar una primera respuesta a esa interrogante considerando la trayectoria del balance migratorio del AMGs en los tres últimos censos, y distinguiendo, a lo menos, dos grandes orígenes y destinos: a) las comunas que no integran el AMGS pero sí forman parte de la RM; y $b$ ) las comunas que no pertenecen a la RM. Además el cuadro 2 proporciona antecedentes más detallados sobre la migración por sexo y escolaridad. ${ }^{14}$

Los resultados sugieren que: $a$ ) igual que aconteció con otras áreas metropolitanas (Rodríguez, 2004), el AMGS de Chile pasó de tener un saldo migratorio positivo -que en todo caso desde el decenio de 1970 representó una fracción secundaria de la expansión de la población metropolitana (Rodríguez, 2004 y 1993) - a uno negativo del orden de 50000 personas en el periodo 1997-2002; b) la inversión de su balance migratorio obedece simultáneamente a una pérdida de atractivo para los inmigrantes -que cayeron desde 250000 en el periodo 1977-1982 a 230000 en el periodo 1997-2002- y a una pérdida de la capacidad de retención de su población -tendencia más marcada que la anterior, pues los emigrantes pasaron de 135000 entre 1977 y 1982 a 280000 entre 1997 y 2002-; c) la amplia mayoría de los emigrantes se dirige hacia comunas fuera de la RM; $d$ ) el flujo de salida que más ha aumentado es el que se dirige a comunas dentro de la RM, lo que revela una creciente integración del AMGS con zonas que hasta hace poco estaban fuera de su órbita de influencia; $e$ ) el predominio de las mujeres en el flujo hacia la ciudad es sostenido, lo que se vincula con la dinámica del sector servicios, cuya demanda de empleo es selectiva hacia las mujeres; $f$ ) la escolaridad media de los inmigrantes es mayor que la de los emigrantes y que la de los no migrantes, lo que debe ser conside-

${ }^{14}$ Se obtuvo la escolaridad media de toda la población y de las personas de 25 y 39 años con la intención de controlar la estructura etaria y facilitar las comparaciones entre migrantes y no migrantes. Cabe subrayar que este cotejo de escolaridad de inmigrantes y emigrantes no debe ser interpretado como efecto de la migración sobre la escolaridad de la región, pues el cómputo no considera la cuantía de cada grupo y la diferencia entre cada uno de ellos y la escolaridad de los no migrantes. En las páginas siguientes se presenta un procedimiento especialmente diseñado para determinar el efecto de la migración sobre la escolaridad en el lugar de origen y en el de destino. 
rado un primer indicio, aunque no definitivo, de que aun perdiendo población el AMGS sigue ganando recursos calificados por la migración; g) el flujo de emigrantes hacia las comunas externas al AMGs pero que pertenecen a la RM aumentó significativamente su nivel de escolaridad, lo que abona la hipótesis sobre la diversificación de destinos de los migrantes de la elite del AMGS, y en particular con la hipótesis del traslado de dicha elite a los suburbios.

Ahora bien, ¿por qué sigue aumentando el peso del AMGS en el total nacional si pierde población por migración? Dos factores explican esta aparente paradoja: a) niveles de crecimiento natural similares a los promedios nacionales en un contexto de homogeneidad regional de este crecimiento (vid. infra "Hipótesis sobre la convergencia regional"); b) el flujo de inmigrantes internacionales (Rodríguez y González, 2004).

En síntesis, por primera vez en la historia reciente de Chile el AMGS cede población, en términos netos, en su intercambio con el resto del país. El hecho de que sólo uno de cada cuatro emigrantes del AMGS se haya dirigido hacia otras comunas de la RM (58 251 de un total de 218 771) sugiere que la pérdida de atractivo no es ficticia ("desconcentración concentrada") sino que obedece a la creciente absorción de flujos migratorios de otros centros urbanos, en su mayoría localizados en regiones dinámicas o que se han convertido en nodos articuladores de regiones. Con todo, los antecedentes muestran que el AMGS sigue siendo el principal ámbito receptor de migrantes internacionales, lo que compensa parcialmente su pérdida de atractivo para los migrantes internos, y también que los niveles educativos de quienes se dirigen al AMGS superan largamente a los de los no migrantes y a los de los migrantes, lo que sugiere que al menos en materia de recursos humanos el AMGS sigue ganando por la migración.

\section{Hipótesis sobre la convergencia regional}

Convergencia de comportamientos y dinámicas demográficas

En términos demográficos, la convergencia entre regiones atañe, en primer lugar, a la reducción de las disparidades en materia de crecimiento de la población. La convergencia en este plano se manifiesta como una tendencia decreciente del coeficiente de variación 


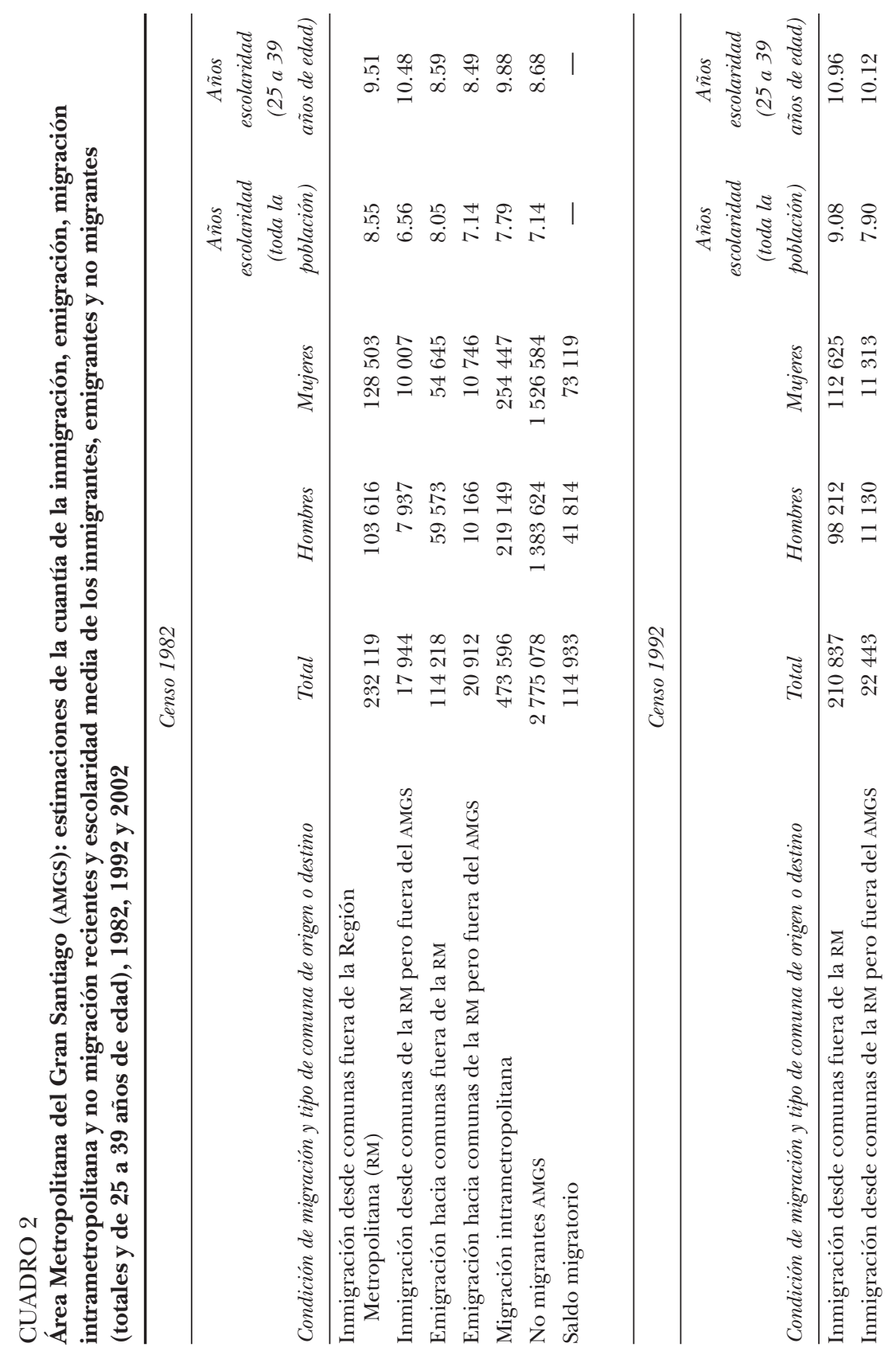




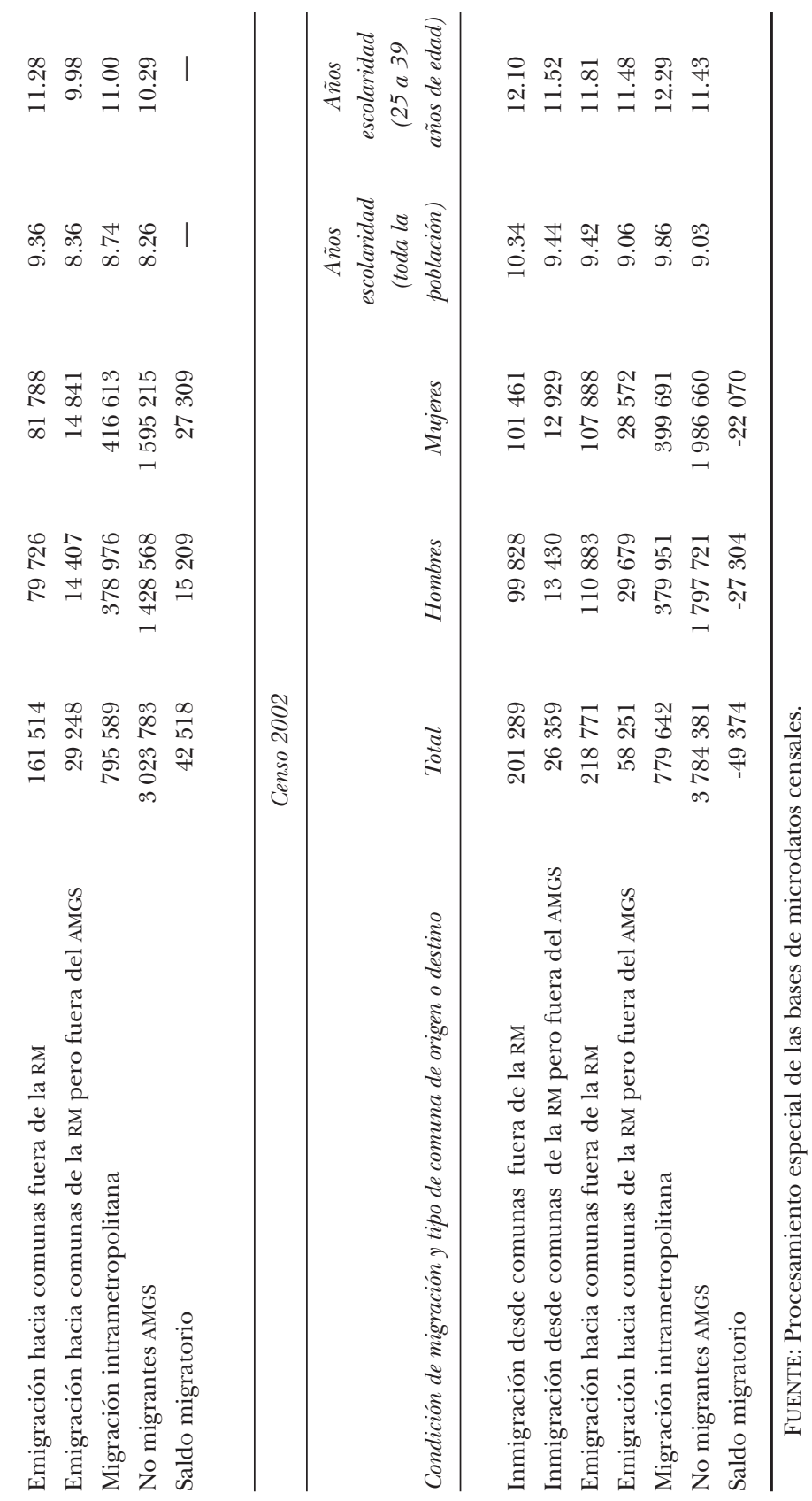


de la distribución de las tasas de crecimiento demográfico regional. ${ }^{15}$ No hay duda de que el crecimiento de las regiones ha sido heterogéneo, como lo evidencia la gráfica 1 , pero la prueba fehaciente para la hipótesis es determinar si dicha heterogeneidad crece, se mantiene o baja. Las cifras que se presentan en la gráfica 2 son erráticas y, por tanto, sugieren la ausencia de un patrón definido de convergencia. En efecto, mientras el decenio de 1980 parece haber sido de convergencia, el de 1990 no lo ha sido y, por ende, la conclusión muestra un patrón más bien volátil.

Ahora bien, los diferenciales regionales en materia de natalidad, mortalidad y crecimiento vegetativo en Chile son moderados o bajos. El examen de las estadísticas vitales entre 1992 y 2000 lleva a concluir que la tasa bruta de natalidad promedio del periodo tuvo un coeficiente de variación de $7.6 \%$ entre regiones; la tasa bruta de mortalidad de $12.1 \%$, y el crecimiento vegetativo de $14.3 \%$ mientras que el crecimiento total fue de $38.6 \%$, lo que sugiere que la migración desempeña el papel principal en las disparidades regionales del crecimiento demográfico. Más significativo aún es el hallazgo que resulta de la estimación indirecta de la fecundidad ${ }^{16}$ por regiones para los censos de 1982, 1992 y 2002: hay una tendencia sostenida y marcada hacia la reducción de la heterogeneidad regional, pues de un coeficiente de variación de $25 \%$ en 1982 se llega a 6\% en 2002 (gráfica 3); cabe decir que en lo que atañe a comportamientos reproductivos las diferencias entre regiones son exiguas en la actualidad. Incluso si se considera la tasa de fecundidad adolescente ${ }^{17}$ la disparidad entre regiones es baja, pues su coeficiente de variación en 2002 era de 12 por ciento. ${ }^{18}$

Aunque discrepan de la tendencia a la igualación de parámetros demográficos, las disparidades socioeconómicas entre regiones están

${ }^{15}$ La desviación estándar no es útil en este caso porque, como se aprecia en la gráfica 1, todas las tasas de crecimiento demográfico de las regiones han tendido a bajar y, por ende, también lo ha hecho la desviación estándar, sin que eso signifique una reducción de la heterogeneidad. El coeficiente de variación controla este factor exógeno, ya que normaliza por la media de la distribución (en este caso obtenida como promedio simple de la distribución de la tasa de crecimiento demográfico por región).

${ }^{16}$ Usando P/F de Brass que incluye la aplicación ZONPLAN de Redatam.

${ }^{17}$ Una conducta que aún diferencia significativamente a los grupos sociales en Chile, pues cálculos basados en los microdatos del censo de 2002 indican que las muchachas del tercil socioeconómico inferior tienen una probabilidad de ser madres antes de los 20 años, equivalente a tres veces la de las muchachas del tercil superior.

${ }^{18}$ En este caso no ha habido tendencia a la convergencia entre las regiones, pues la heterogeneidad de la distribución de las tasas de fecundidad adolescente regionales se ha mantenido estable entre 1982 y 2002, lo que ratifica la peculiaridad de esta fecundidad respecto de las otras edades (Rodríguez, 2005). 


\section{GRÁFICA 2}

Chile: evolución de la heterogeneidad de las tasas de crecimiento demográfico entre regiones, 1970-2002

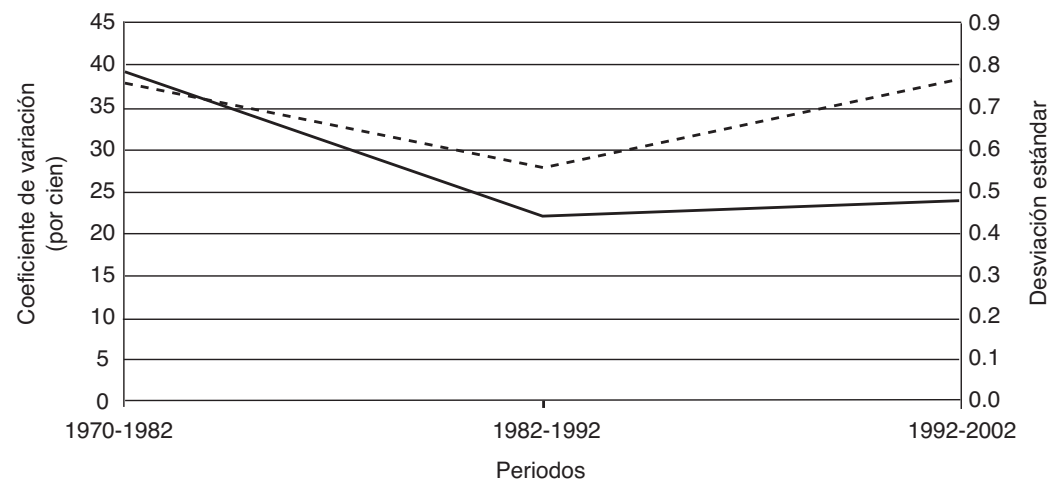

FUENTE: Elaboración propia con base en los datos del cuadro 1.

lejos de desaparecer; más aún, en áreas como la de la pobreza han aumentado, pues el coeficiente de variación de la distribución del porcentaje de hogares pobres por región creció de 19 a 30\% entre 1990 y 2003. ${ }^{19}$ Según la Casen, en 2003 los niveles de pobreza en el hogar iban desde índices inferiores a 10\% en regiones como Antofagasta y Magallanes a 25\% en Araucanía (www.mideplan.cl). De lo anterior se desprende que deben existir fuerzas culturales o políticas públicas con capacidad para actuar en todo el país homogeneizando valores y actitudes en el plano de la reproducción, así como el acceso a medios anticonceptivos modernos. Para precisar estas fuerzas y los canales mediante los cuales actúan se requiere más investigación. Cualquiera que sea el caso, la conclusión es que a diferencia de lo que parece estar aconteciendo en materias económica y social, en el plano reproductivo hay claros signos de convergencia entre regiones.

${ }^{19}$ Cálculos basados en datos disponibles en www.iasuchile.cl/files/biblioteca/casen 2000.pdf para 1990 y en el procesamiento en línea de la encuesta Casen en 2003 (www. mideplan.cl). Cabe anotar que esta alza ocurrió en el contexto de una reducción generalizada de la pobreza en todas las regiones del país. 
GRÁFICA 3

Chile: evolución de la heterogeneidad de la tasa global de fecundidad entre regiones, 1982-2002

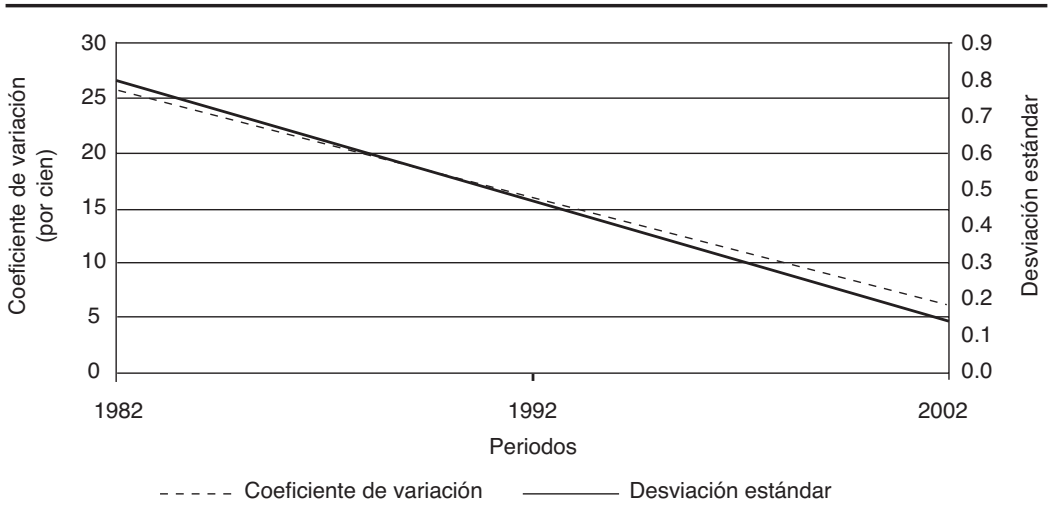

FUENTE: Elaboración propia con base en procesamientos especiales de los microdatos con la aplicación ZONPLAN de Redatam.

Migración entre regiones y convergencia

Como se planteó en el capítulo inicial, algunas investigaciones sugieren que la migración no favorece la convergencia económica (Fuentes, 1997). No hay duda de que la migración tiene efectos en los balances sociales entre territorios. Uno de los hallazgos sistemáticos en este plano se refiere al envejecimiento en las zonas de emigración neta por la selectividad juvenil de la migración; tal envejecimiento, por lo mismo, suele coexistir con un alto peso de población infantil, y esto genera una situación de alta dependencia demográfica en las zonas expulsoras. Un debate abierto y con poca evidencia sistemática acumulada atañe al efecto de la migración interna sobre el capital humano regional y, en esa línea, sobre el cierre o ensanchamiento de brechas regionales en este plano. Si bien se sospecha que la migración podría agudizar las disparidades de recursos humanos entre regiones, porque los migrantes más capacitados encuentran incentivos para trasladarse a las regiones con más recursos materiales y humanos, también hay razonamientos e indicios en sentido contrario (Rodríguez, 2004; Aroca, 2004; Greenwood, 1997).

El procesamiento de los microdatos censales con Redatam es un procedimiento novedoso que facilita la obtención de antecedentes 
empíricos sobre este asunto. Se trata de la construcción de matrices de migración donde los valores de las celdas no son personas sino atributos del flujo. ${ }^{20}$ Los marginales de tales matrices -conforme a un supuesto de constancia del atributo para cada persona durante el periodo de referencia, lo que es obvio en características como el sexo, pero improbable en atributos como los ingresos- pueden interpretarse como el valor regional en el momento inicial (cinco años antes del censo) y en el momento final (fecha del censo), y su diferencia como el cambio en el atributo debido exclusivamente al efecto de la migración (no hay mortalidad ni fecundidad ni modificación del atributo en el tiempo de referencia). En el caso de los recursos humanos regionales, este procedimiento se ha aplicado para estimar el efecto de la migración sobre el promedio de años de estudio, lo que requiere efectuar los cálculos con un grupo cuya escolaridad pueda suponerse invariable en los cinco años previos al censo (Rodríguez, 2004).

El cuadro 3 muestra un resumen de la aplicación de este procedimiento a los tres últimos censos de Chile. Para el supuesto de invariabilidad de la educación se restringieron los cálculos a los jefes de hogar, ya que casi todos ellos llevan bastante tiempo fuera del sistema educativo. Los resultados sugieren un impacto más bien moderado abajo de la migración sobre los niveles educativos regionales, ya que el efecto más grande lo exhibe la XI Región de Aysén, que en el periodo 19771982 incrementó su escolaridad media casi 3\% como resultado de la migración. Los datos del cuadro 3 permiten efectuar una estimación sintética de la relación entre el nivel educativo medio de las regiones y el efecto de la migración sobre la educación. Si las regiones con niveles educativos promedio más elevados son las que aumentan su escolaridad media como resultado de la migración, la conclusión sería que la migración acentúa las disparidades entre las regiones en materia de capital humano. Los resultados de las correlaciones simples entre el nivel educativo de las regiones en el momento inicial de la medición y el efecto de la migración sobre la educación en el periodo sugieren que

\footnotetext{
${ }^{20}$ Esta matriz se construye con la matriz tradicional de personas que clasifica a los individuos según su lugar de residencia actual y el que tenían en una fecha fija del tiempo anterior (típicamente cinco años) y una nueva en la cual se suma el aporte de cada persona del flujo en un atributo dado (por ejemplo: edad) y se obtiene un valor acumulado en cada celda de dicho atributo. Finalmente, se calcula una tercera matriz que resulta de la división de la segunda entre la primera y cuyas celdas contienen la media del atributo para cada flujo. Para más detalles véase Rodríguez, 2004 o www.cepal. org/celade (base de datos MIALC). Para antecedentes más generales véase el artículo de Acuña y Rodríguez (2004).
} 


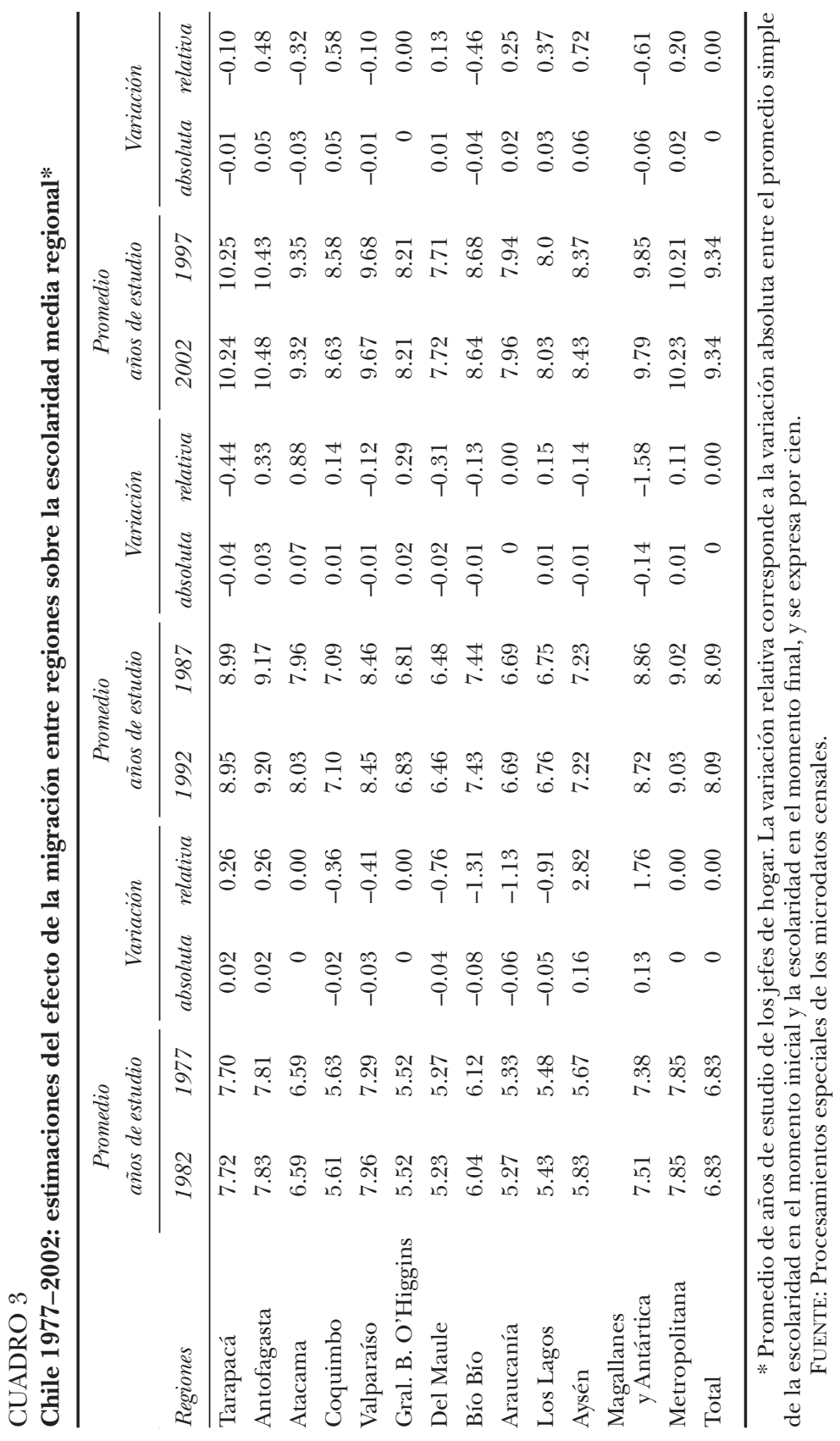


mientras entre 1977-1982 la migración ensanchaba las disparidades entre las regiones (coeficiente positivo de 0.25 ), en los otros dos periodos ha tendido a reducirlas, aunque de manera leve (coeficientes negativos de -0.23 y -0.27 , respectivamente). Es decir, al menos en lo que respecta a esta dimensión simple del capital humano regional, la migración contribuiría, aunque de manera exigua, a la convergencia entre regiones.

\section{Sobre la segregación}

Respecto a la segregación residencial, contrastan el voluminoso caudal de opiniones que sugieren que estaría aumentando en el AMGS (Rodríguez y Winchester, 2001) y los escasos estudios empíricos que en general no llegan a esa conclusión (Arriagada y Rodríguez, 2004; Rodríguez, 2001; Sabatini, Cáceres y Cerda, 2001). Esta discrepancia entre la percepción y la realidad tiene dos componentes.

El primero es metodológico y se relaciona con la complejidad que entraña medir la segregación residencial socioeconómica. Esto se debe a que la mayor parte de los índices que suelen usarse para ello se confeccionaron con el propósito de medir la segregación residencial racial, en cuyo caso los grupos son categorías relativamente fáciles de distinguir, muchas veces dicotómicas, lo que no ocurre con los grupos socioeconómicos que previamente deben definirse conceptual y operativamente, y los resultados de la medición dependen de dicha definición. A lo anterior se añade el denominado "efecto escala", porque cualquier medición de la segregación depende críticamente del grado de desagregación geográfico usado; no es descartable, entonces, que en una misma ciudad y con los mismos datos e indicadores se pueda llegar a la conclusión de que la segregación aumentó y disminuyó simultáneamente (por ejemplo: disminuyó entre comunas pero aumentó entre barrios).

El segundo componente es empírico y se origina en el contrapunto de dos procesos de configuración social de la ciudad. Por una parte está el proceso histórico de concentración de la riqueza y expulsión de la pobreza en la zona oriente del AMGS que abona la imagen de una ciudad dual con una segregación residencial intensa y a gran escala. ${ }^{21}$

${ }^{21}$ La zona oriente de la ciudad -cuyo núcleo son las comunas Providencia, Vitacura y Las Condes pero cuya superficie total incluye partes significativas de las comunas Lo Barnechea, La Reina y Nuñoa- disfruta de una situación socioeconómica muy superior al resto del AMGS. Por ejemplo, según el censo de 2002 la media de escolaridad de los jefes de hogar era del orden de nueve años, mientras en las mencionadas comunas 
En otra parte está el traslado, relativamente novedoso, de familias de estrato medio y alto hacia comunas de expansión urbana o incluso externas al AMGS. En el decenio de 1980 este fenómeno afectó básicamente a algunas familias de estrato medio que se trasladaron a comunas como La Florida y Maipú y a familias de estrato alto que se movieron hacia la comuna de Lo Barnechea. En el decenio de 1990 estos movimientos se hicieron más complejos y amplios e hicieron evidente una mudanza original dentro de la elite, que comenzó a salir de su enclave tradicional y se dirigió hacia sectores aledaños o hacia zonas más bien rurales con reciente conexión vial de buena calidad con el AMGS. Este último proceso, conocido como rururbanización (Rodríguez, 2002; Armijo, 2000; Barros, 1999) y extendido en varias metrópolis de la región, se expone en el cuadro 2, donde se advierte el fuerte aumento de la emigración desde el AMGS hacia otras comunas de la Región Metropolitana: 21000 en 1977-1982; 29000 en 1987-1992 y 58000 en 19972002, con un aumento del nivel educativo de este flujo de 8.5 a 11.5 años. Este nuevo frente de poblamiento ha tendido a ampliar el área de influencia de Santiago, que ya estaba extendiéndose como resultado de las mejoras viales y de transporte. En efecto, la población de las comunas donde se concentran los asentamiento rururbanos, en su mayoría constituidos por urbanizaciones de lujo, condominios cerrados y parcelas de agrado, depende totalmente de la ciudad, lo que corrobora el que $30 \%$ o más de su población deba viajar diariamente a la ciudad para trabajar, estudiar o hacer compras (González y Rodríguez, 2004). Por cierto, la localización de esta población tiene consecuencias en el largo plazo porque constituye un factor dinamizador del mercado inmobiliario y un factor de presión para la extensión de servicios y red vial. Así, este comportamiento migratorio emergente de la elite, que tuvo como antecedentes la apertura de conexiones viales y la virtual saturación de su hábitat histórico, ha pasado a ser una nueva y poderosa fuerza en la configuración de la ciudad.

superaba 13 años (va desde 12 años en Lo Barnechea a casi 15 años en Vitacura). Según la encuesta Casen 2000, en materia de ingreso la disparidad era mayor, pues el promedio por hogar en la Provincia de Santiago era cercano a 700000 pesos (1 100 dólares de Estados Unidos) mientras que en Las Condes superaba 2 millones de pesos (3000 dólares de Estados Unidos) (procesamiento en línea en www.mideplan.cl). Por otra parte, si bien estas comunas sumadas en 2002 representaban 15\% de la PEA del AMGS, concentraban $60 \%$ de los empleadores con estudios universitarios, segmento esencial de la elite socioeconómica del país (mapa 2). Pero tal vez lo más relevante de estas comunas para efectos de segregación residencial socioeconómica sea su virtual ausencia de pobres: de las tres con datos representativos a escala comunal en la Casen 2000 (Las Condes, Nuñoa y La Reina) ninguna tenía más de $2 \%$ de hogares bajo la línea de pobreza (www.mideplan.cl). 
La colisión de estos dos procesos genera un área de ambigüedad respecto de las tendencias de la segregación. Por cierto, el elevado nivel de segregación residencial socioeconómica en el AMGS no está en discusión (Arriagada y Rodríguez, 2004); además, de los estudios comparativos se deduce que es una de las ciudades más segregadas de la región (Arriagada y Rodríguez, 2004; Dureau et al., 2002; Kaztman y Wormald, 2002). Sin embargo, de lo anterior no se colige que la segregación haya estado aumentando en los últimos años. El cuadro 4 ilustra ambos fenómenos. Por una parte, el índice de disimilitud a escala comunal de 2002 es de $47 \%$ en el caso de la elite (cuyos jefes de hogar se declaran empleadores y tienen educación universitaria), lo que quiere decir que habría que redistribuir a casi la mitad de este grupo por las comunas pobres del AMGS para lograr una representación de la elite en cada comuna equivalente al peso de la elite en el AMGS. Cabe recordar que en Estados Unidos un índice superior a $60 \%$ se considera hipersegregación. ${ }^{22}$ Pero el cuadro 4 también muestra que la segregación tendió a reducirse para la elite en particular entre 1982 y 1992.

Ahora bien, los datos no apoyan la hipótesis de que la migración intrametropolitana contribuye a la convergencia entre comunas. Por el contrario, hay indicios de que en el periodo 1997-2002 tuvo un efecto amplificador de las brechas entre comunas ricas y pobres. La gráfica 4 es ilustrativa, pues hay una correlación positiva entre la ganancia educativa por migración y el nivel educativo inicial de la comuna. Así, aunque aparecen comunas periféricas beneficiadas por la migración -de bajo nivel educativo inicial y alta ganancia en el periodo debida a la migración- básicamente porque reciben migrantes con alta educación provenientes del oriente de la ciudad, no son suficientes para contrarrestar el efecto dominante, que es la captura de los migrantes más calificados por las comunas más ricas. En suma, hay indicios de que la reducción detectada de los índices de segregación no podría explicarse solamente por el derrame de la elite. Otras fuerzas, como una tendencia al aumento de la escolaridad media más intenso en las comunas con menos educación, parecen ser importantes para la tendencia de estos índices agregados de segregación residencial. ${ }^{23}$

22 "Generally, dissimilarity measures above $60 \%$ are thought to represent hypersegregation" (http://mimh200.-mimh.edu/PieDb/04476.pdf).

${ }^{23}$ Esto último se refleja claramente en el índice de correlación simple entre el nivel de escolaridad de los jefes de hogar por comuna en 1992 y el cambio de dicho nivel entre 1992 y 2002, que es de -0.557 , lo que indica que en promedio los menores niveles de escolaridad inicial se asociaron con las mayores ganancias en el periodo de referen- 


\section{MAPA 2}

AMGS: cinco primeras comunas de la jerarquía de comunas según proporción que representa la elite socioproductiva respecto de su PEA, 2002*

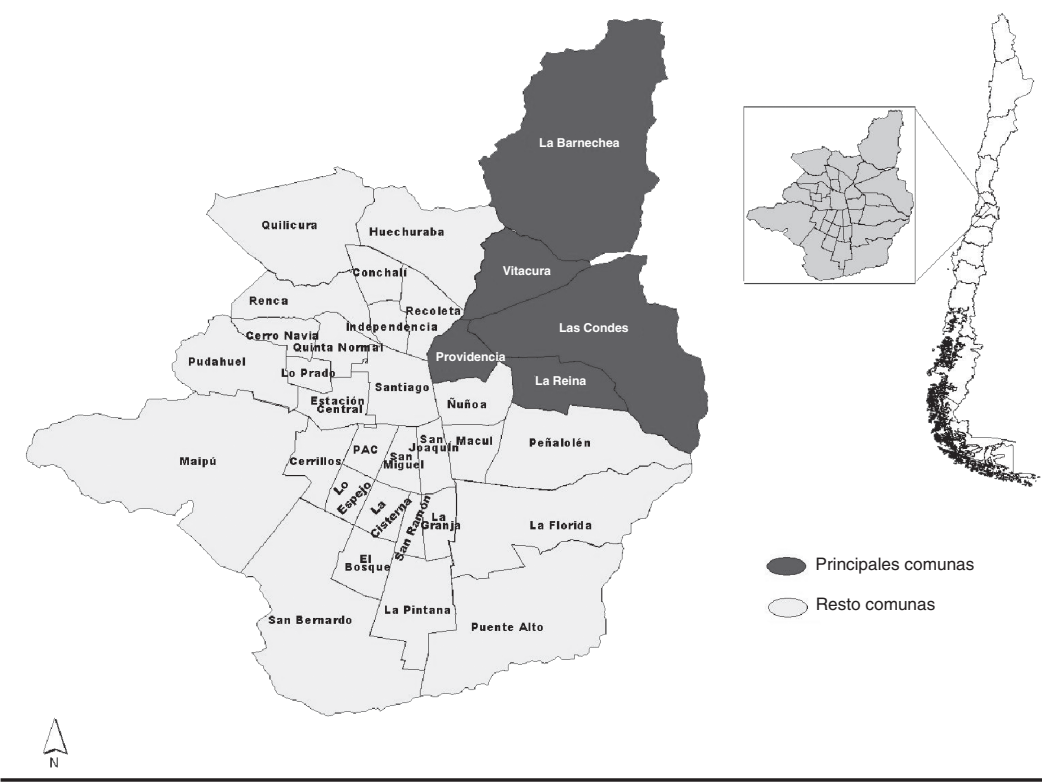

* Empleadores con educación superior.

Nota 1: PAC: comuna de Pedro Aguirre Cerda.

NotA 2: Algunas comunas (Lo Barnechea, La Florida, Maipú, Pudahuel) presentan modificaciones en sus límites y sólo muestran las zonas urbanas.

FUENTE: Procesamiento especial en Redatam para el Censo de 2002.

CUADRO 4

AMGS: evolución del índice de disimilitud para dos segmentaciones socioeconómicas de los jefes de hogar, 1982, 1992 y 2002 (porcentajes)

\begin{tabular}{ccc}
\hline & $\begin{array}{c}\text { Empleadores } \\
\text { Año }\end{array}$ & $\begin{array}{c}\text { Asalariados } \\
\text { con educación universitaria }\end{array}$ \\
\hline 1982 & 57 & 25 \\
1992 & 49 & 23 \\
2002 & 47 & 23 \\
\hline
\end{tabular}

FUENTE: Elaboración propia con base en el procesamiento especial de las bases de microdatos censales. 


\section{Conclusiones, insumos de políticas y desafíos}

La evidencia sistematizada y desplegada en este trabajo contribuye a aportar elementos para el debate sobre las tendencias de la distribución espacial y la movilidad territorial de la población chilena. Las principales conclusiones son:

a) Los flujos migratorios del último periodo censal revelan quiebres respecto de las tendencias históricas; destacan al respecto la migración neta negativa de la Región Metropolitana y la condición de atracción neta de tres regiones históricamente expulsoras -la IV, la VI y la X-a la par de un emergente dinamismo productivo en ellas vinculado con las actividades exportadoras. Estos hallazgos abonan la hipótesis de desconcentración regional. Sin embargo esto no se ha reflejado en el peso demográfico de la Región Metropolitana, porque su crecimiento natural ha rebasado la media nacional y porque la migración internacional se dirigió mayoritariamente a Santiago.

b) El Área Metropolitana del Gran Santiago (AMGS) también registró emigración neta negativa en el periodo 1997-2002, lo que no tiene parangón en la historia estadística del país. Aunque en el flujo hacia el AMGS siguen predominando las mujeres, la selectividad femenina ha tendido a bajar, lo que puede estar relacionado con cierto declive de nichos laborales para las mujeres migrantes (en particular el servicio doméstico, aunque también aquí cabe la sustitución por migrantes internacionales). Cabe consignar que pese a esta nueva condición de perdedora de población por migración interna, el AMGS todavía resulta beneficiada por el intercambio migratorio, pues el nivel educativo de los inmigrantes supera al de los emigrantes.

c) La información de migración entre comunas permite detectar una creciente emigración desde el AMGS hacia localidades cercanas. El rasgo más novedoso de estos traslados en el decenio de 1990 es que tuvieron una alta participación de familias

cia. Esto último forma parte de un proceso de aumento sostenido de la escolaridad en toda la estructura social de Chile (y de todo el territorio del país), que ha hecho que las brechas entre grupos sociales y ámbitos geográficos en materia de cantidad de años de escolaridad (que no forzosamente en calidad de la educación) se estrechen. La migración intrametropolitana, según la evidencia presentada en este trabajo, apunta en la dirección contraria, pero su efecto no logra contrarrestar la tendencia inercial hacia una reducción de la desigualdad social y territorial en materia de años de escolaridad. 

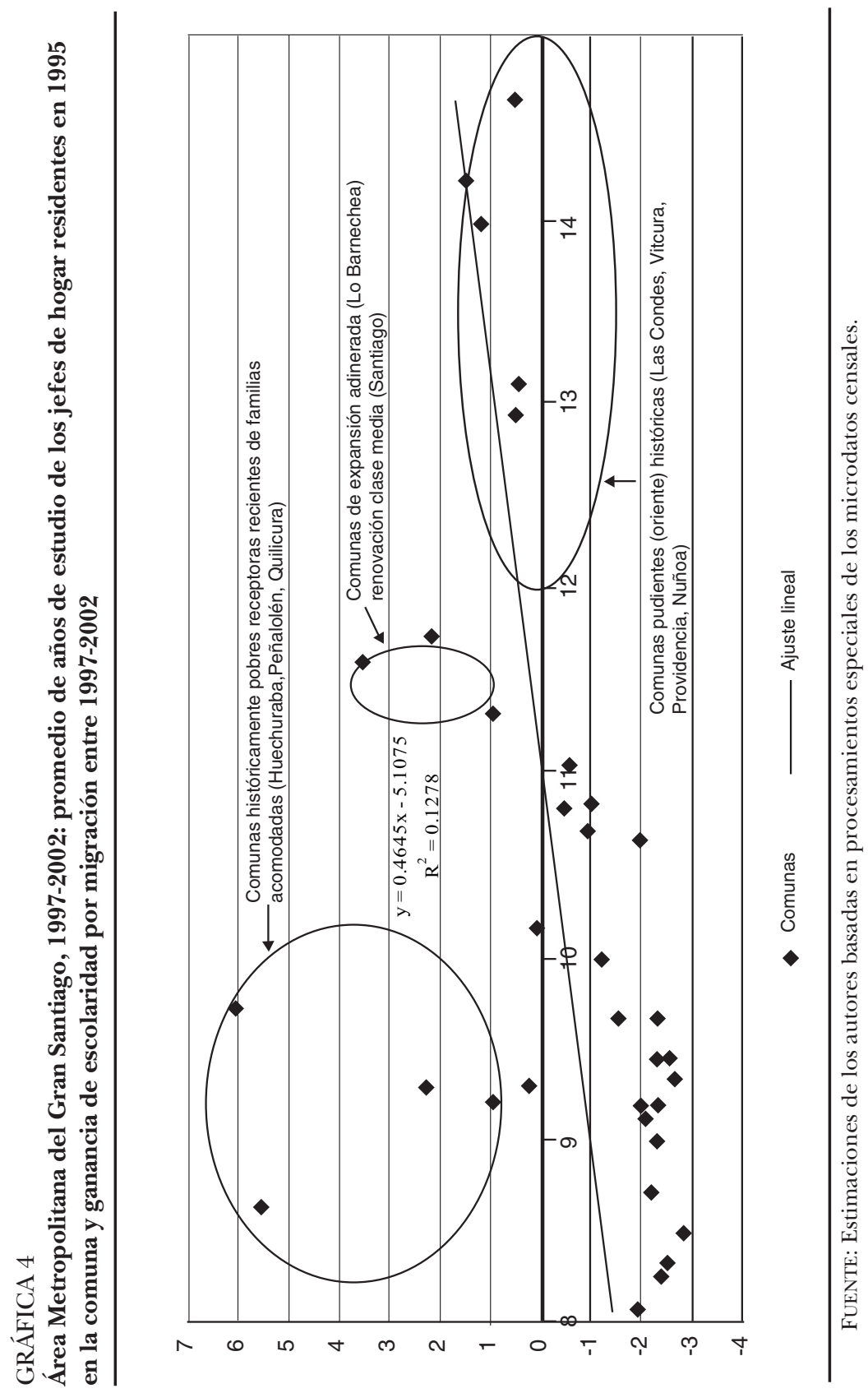
de estrato alto, que abandonaron el histórico reducto de las clases acomodadas (el oriente de la capital) y se dirigieron hacia ámbitos de paisaje rural, pero en general bien equipados, con servicios básicos completos y bien conectados con la ciudad. Este tipo de desplazamiento hace más "difusa" la ciudad e introduce más mezcla socioeconómica en la periferia, sin que ello signifique forzosamente mayor interacción entre grupos socioeconómicos.

d) Pese a este aumento de la migración hacia localidades cercanas, puede descartarse que tras esa emigración neta de la ciudad haya una "desconcentración concentrada", pues el crecimiento demográfico más acelerado y los mayores índices de atractivo migratorio corresponden a localidades articuladoras de economías regionales más bien distantes de Santiago.

e) Las diferencias de fecundidad y de mortalidad entre regiones son bajas y decrecientes, de ahí que el crecimiento natural entre ellas tienda a la convergencia. Sin embargo, las disparidades regionales en otros planos -como el dinamismo económico, la creación de puestos de trabajo y los índices de pobreza- no parecen estrecharse, lo que augura una continuidad de los movimientos entre regiones, ya que en gran medida responden a la existencia de desigualdades entre ellas.

f) Usando un procedimiento novedoso que estima los niveles de educación de las regiones sin y con migración y luego los coteja para evaluar el efecto de la migración sobre la educación en cada una de ellas, se concluye que su impacto es entre moderado y bajo. Ahora bien, mientras en el decenio de 1970 tendía a ensanchar las distancias educativas entre las regiones, en los decenios de 1980 y 1990 ha contribuido, aunque muy modestamente, a su convergencia.

g) Aunque la ciudad registra altos niveles de segregación residencial -en un somero examen, más bien visual, se presta claramente para la calificación de ciudad "dual"- y es creciente la preocupación por el tema, no hay indicios de que tal segregación haya aumentando en los últimos 15 años. Esto no se ha debido a una apertura de los barrios de la elite, pues han tendido a expulsar casi totalmente a los bolsones de población pobre que tenían. Su causa estriba en el ya mencionado traslado de algunas familias de la elite hacia zonas periféricas y también en la paulatina ocupación de comunas periféricas por 
familias de clase media. Con todo, las diferencias en materia de indicadores sociales y demográficos dentro de la ciudad son mucho más abultadas que las que se verifican entre regiones, y constituyen un motivo de preocupación por las implicaciones que tienen para el ejercicio de la ciudadanía, la reproducción de la pobreza, la gobernabilidad metropolitana y las finanzas locales.

h) De acuerdo con el efecto de la migración metropolitana sobre el acervo de recursos humanos es posible identificar tres grandes grupos de comunas dentro del AMGS: las acomodadas del oriente, que sin excepción incrementan su nivel educativo con la migración intrametropolitana; las pobres, que han recibido el derrame de la elite y que claramente aumentan su nivel educativo con las mudanzas dentro de la ciudad; y el resto, que tiende a reducir su nivel educativo con los traslados, complicando aún más su difícil situación.

Tanto las tendencias que continúan como las que emergen tienen consecuencias prácticas. Hay indicios de que la migración está actuando como mecanismo consistente con la dinámica productiva, de manera tal que la población se traslada hacia regiones con economías más activas, lo que favorece simultáneamente al país y a las personas. Sin embargo, la disociación entre el crecimiento económico y la creación de empleos en algunas regiones hace que esta redistribución "afín" con el dinamismo económico tenga restricciones. De cualquier manera, las políticas públicas deberían procurar que estos traslados internos efectivamente se dirijan hacia las zonas dinámicas y evitar que las zonas deprimidas entren en una trampa "centrífuga" donde el estancamiento, la pérdida de recursos humanos, el desaliento y el estigma refuercen su declinación.

Para las autoridades locales y regionales, los antecedentes presentados ofrecen órdenes de magnitud del cambio en los requerimientos de servicios básicos en sus respectivas jurisdicciones; en particular proporcionan estimaciones de presiones adicionales para la infraestructura y los servicios regionales y nuevos requerimientos para la inserción exitosa de los inmigrantes. También sugieren la pertinencia de acciones destinadas a actuar sobre la composición de los flujos incentivando la llegada de recursos humanos calificados o evitando su partida. Para las autoridades metropolitanas, la continuación del poblamiento periférico entraña grandes desafíos, sobre todo si conduce 
a la constitución de áreas eminentemente pobres, carentes de servicios, con escaso capital social y graves problemas de conectividad. Se trata de condiciones explosivas, con frecuencia ocultas bajo una aparente solidez habitacional, que requieren de intervenciones integrales que forzosamente deben contar con recursos centrales, ya que los municipios carecen de financiamiento para ello. Como contrapartida, la configuración de una metrópoli difusa y la aparición del fenómeno "rururbano" entraña un escenario nuevo con potencialidades y riesgos. Un punto importante es que una vez consolidada esta disposición a "derramarse" entre la elite, ciertas decisiones públicas, como las relativas a límites urbanos, condiciones de edificación y construcción de vialidad o medios de transporte, pueden generar en este grupo procesos de redistribución territorial significativos.

Por último, la consolidación de un grupo mayoritario de comunas pobres que pierde recursos humanos por migración simboliza la trampa de pobreza que genera descentralización y municipalización en un área metropolitana con tan grandes contrastes entre comunas. La acción de fondos redistributivos, así como la selectividad territorial de los programas sociales centrales parecen clave para contrarrestar al menos parcialmente los impresionantes desequilibrios de recursos entre los municipios ricos y los pobres.

\section{Bibliografía}

Acuña, M. y J. Rodríguez (2004), Redatam Informa, núm. 10. Disponible en: www.cepal.org/publicaciones/Poblacion/1/LCL2261/RI2005_vol10. pdf.

Acuña, M. y J. Rodríguez (2004), "Explotando el módulo sobre migración interna de los censos de población y vivienda de América Latina y el Caribe”, Redatam Informa, núm. 10, Celade, División de población de la CEPAL (LC/L.2261/E).

Arroyo, M. (2001), "La contraurbanización: un debate metodológico y conceptual sobre la dinámica de las áreas metropolitanas", Papeles de Población, año 7, núm. 30, pp. 93-129.

Armijo, G. (2000), La urbanización del campo metropolitano de Santiago: crisis y desaparición del hábitat rural. Disponible en: www.uchile.cl/facultades/ arquitectura/urbanismo/revurbanismo/n3/armijo/armijo.html.

Aroca, P. (2004), "Migración intrarregional en Chile. Modelos y resultados 1987-2002”, Notas de Población, núm. 78, Celade, División de Población de la CEPAL (LC/G.2229-P). 
(2003), "Migración interregional en Chile. Modelos y resultados 19772002”, Santiago de Chile, Celade (mimeo.).

—, G. Hewings y J. Paredes (2001), "Migración interregional y el mercado laboral en Chile", Cuadernos de Economía (Latin American Journal of Economics), vol. 38, núm. 5, pp. 321-245.

Arriagada, C. y J. Rodríguez (2004), "Segregación residencial en la ciudad latinoamericana", Eure, Revista Latinoamericana de Estudios Urbano Regionales, vol. 30, núm. 89, mayo, pp. 5-24.

Barros, C. (1999), "De rural a rururbano: transformaciones territoriales y construcción de lugares al sudoeste del Área Metropolitana de Buenos Aires”, Scripta Nova, Revista Electrónica de Geografía y Ciencias Sociales, núm. 45. Disponible en: www.ub.es/geocrit/sn-45-52.htm.

Benko, G. y A. Lipiez (eds.) (2000), La richesse des régions. La nouvelle géographie socio-économique, París, PUF.

Boisier, S. (1997), "La geografía de la globalización: un único espacio y múltiples territorios", Anales 1: Desafíos y perspectivas de la descentralización, Caracas, Centro Latinoamericano de Administración para el Desarrollo, CLAD, pp. 27-47.

Caravaca, I. (1998), "Los nuevos espacios ganadores y emergentes”, Eure, Revista Latinoamericana de Estudios Urbano Regionales, vol. 24, núm. 73.

Castells, M. (1997), La era de la información: economía, sociedad y cultura, Madrid, Alianza Editorial.

(1989), The Informational City: Information Technology, Economic Restructuring, and the Urban-Regional Process, Oxford, Blackwell.

Celade (1984), "Políticas de redistribución de la población en América Latina", Notas de Población, año 12, núm. 34, pp. 79-114.

— CEPAL (2005) “América Latina: urbanización y evolución de la población urbana, 1950 -2000”, Boletín Demográfico, núm. 75. Disponible en: www. cepal.org/celade.

Cuervo, L. (2003), "Evolución reciente de las disparidades económicas territoriales en América Latina: estado del arte, recomendaciones de política y perspectivas de investigación", Gestión Pública, núm. 41, CEPAL/ILPES (LC/L.2018-P/E).

Cuervo, L. y J. González (1997), Industria y ciudades en la era de la mundialización. Un enfoque socioespacial, Bogotá, Tercer Mundo.

Curran, S. y E. Rivero-Fuentes (2003), "Engendering Migrant Networks: The Case of Mexican Migration”, Demography, vol. 40, núm. 2, pp. 289-307.

Daher, A. (2003), "Regiones-commodities. Crisis y contagio en Chile”, Eure, Revista Latinoamericana de Estudios Urbanos Regionales, vol. 29, núm. 86, pp. 89-108.

(1998), "Privatización y regionalización en Chile", en Carlos Antonio De Mattos, Daniel Hiernaux y Darío L. Restrepo Botero (comps.), Globalización y territorio: impactos y perspectivas, Santiago, Instituto de Estudios Urbanos/Fondo de Cultura Económica, pp. 307-335. 
(1994), “Competencia: regiones ganadores y perdedoras en Chile”, Eure, Revista Latinoamericana de Estudios Urbano Regionales, vol. 20, núm. 60, agosto, pp. 63-84.

De Mattos, C. (1999), "Santiago de Chile, globalización y expansión metropolitana: lo que existía sigue existiendo", Eure, Revista Latinoamericana de Estudios Urbano Regionales, vol.25, núm.76, pp. 29-56.

- (2002), "Mercado metropolitano de trabajo y desigualdades sociales en el Gran Santiago: ¿una ciudad dual ?”, Eure, Revista Latinoamericana de Estudios Urbano Regionales, vol. 28, núm. 85, pp. 51-70.

- (2001), "Metropolización y suburbanización", Eure, Revista Latinoamericana de Estudios Urbano Regionales, vol. 27, núm. 80, pp. 5-8.

De Mattos, C. y M. Guerra Medina (1993), Impactos territoriales de la modernización capitalista en Chile: $\underset{\complement}{E}$ El despertar de las regiones?, Santiago, Instituto de Estudios Urbanos, Pontificia Universidad Católica (Documentos de trabajo, 174).

- L. Riffo y S. Reyes (2001), "Reestructuración, crecimiento y concentración territorial de la industria: caso de la Región Metropolitana de Santiago", Estadística y Economía, núm. 20, pp. 121-157.

Dureau, F. et al. (coords.) (2002), Metrópolis en movimiento. Una comparación internacional, Bogotá, IRD/Alfaomega.

Flores, C. (2005), "Residential Segregation and the Geography of Opportunities: Spatial Dependence and Spatial Heterogeneity in Education: A Case Study of Santiago", LBJ School of Public Affairs Population Research Center, The University of Texas at Austin. Disponible en: http://utip.gov. utexas.edu/colloquium/flores.pdf.

Frey, W. (1988), "Migration and Metropolitan Decline in Developed Countries: a Comparative Study", Population and Development Review, vol. 14, núm. 4, pp. 595-628.

Fuentes, Rodrigo (1997), “¿Convergen las regiones en Chile? Una interpretación”, en Felipe Morandé y Rodrigo Vergara (eds.), Análisis empírico del crecimiento en Chile, Centro de Estudios Públicos, Programa de Posgrado en Economía, ILADES/Georgetown University, pp. 171-196.

González, D. y J. Rodríguez (2004), “Tendencias de la migración interna en Chile en los últimos 35 años: Recuperación regional selectiva, desconcentración metropolitana y rurubanización”, documento presentado en I Congreso de la Asociación Latinoamericana de Población, ALAP, Caxambú, Brasil, del 18 al 20 de septiembre.

Graeme, H., A. Champion y A. Lattes (2001), "New Conceptualisation of Settlement for Demography: Beyond the Rural/Urban Dichotomy", trabajo presentado en la Conferencia de la IUSSP, Bahía, Brasil.

Graham, S. y S. Marvin (2001), Splitering Urbanism: Networked Infrastructures, Technological Mobilities and the Urban Condition, Londres, Routledge.

Greenwood, M. (1997), "Internal Migration in Developed Countries", en M. Rosenzweig y O. Stark (eds.), Handbook of Families and Population Economics, Amsterdam, Elsevier, pp. 647-720. 
Hidalgo, R., F. Arenas y Quense (s.f.), La ciudad amurallada. Los condominios y los nuevos espacios residenciales en dos comunas del área oriente de Santiago de Chile, 1990-2000, Santiago, Instituto de Geografía, Pontificia Universidad Católica de Chile.

Hurtado, C. (1966), Concentración de población y desarrollo económico. El caso chileno, Santiago, Instituto de Economía, Universidad de Chile (Publicaciones del I.E., 89).

Ingram, G. (1997), Patterns of Metropolitan Development: What Have We Learned?, Washington, BIRF (Policy Research Working Paper, 1841).

Izazola, H. (2004), "Migration to and from Mexico City, 1995-2000”, Environment and Urbanization, vol. 16, núm. 1, pp. 211-230.

Jargowsky, P. (1996), "Take the Money and Run: Economic Segregation in U.S. Metropolitan Areas”, American Sociological Review, vol. 61, núm. 6, pp. 984 998.

Katzman, R. (2003), "La dimensión espacial en las políticas de superación de la pobreza urbana”, trabajo presentado a la Reunión de Expertos en Pobreza Urbana, División de Medio Ambiente y Asentamientos Humanos, Comisión Económica para América Latina y el Caribe (CEPAL), Santiago de Chile, 27 y 28 de enero.

- (2001), "Seducidos y abandonados: el aislamiento social de los pobres urbanos", Revista de la CEPAL, núm. 75, pp. 171-189.

— y G. Wormald (eds.) (2002), Trabajo y ciudadanía. Los cambiantes rostros de la integración y exclusión social en cuatro áreas metropolitanas de América Latina, Montevideo, Sofilco.

Lombardi, M. y D. Veiga (eds.) (1989), Las ciudades en conflicto. Una perspectiva latinoamericana, Montevideo, Banda Oriental.

Lucas, R. (1998), "Internal Migration and Urbanization: Recent Contributions and New Evidence", Boston, Boston University, Institute for Economic Development (Discussion Paper Series, 91).

_ (1997), "Internal Migration in Developing Countries", en M. Rozenweig y O. Stark (eds.), Handbook of Population and Family Economics, Amsterdam, Elsevier, pp. 721-797.

Machado, E. (2001), "Urban Spatial Segregation and Social Differentiation: Foundation for a Typological Analysis", trabajo presentado en el International Seminar on Segregation in the City Lincoln Institute of Land Policy, Cambridge.

Martínez, J. (1999), La migración interna y sus efectos en dieciséis ciudades de Chile, Santiago de Chile, Celade, CEPAL.

Massey, D., M. White y V. Phua (1996), "The Dimensions of Segregation Revisited", Sociological Methods and Research, vol. 24, núm. 2, pp. 172-206.

Mollenkopf, J. y Manuel Castells (eds.) (1991), Dual City: Restructuring New York, Nueva York, Russell Sage Foundation.

Montgomery, M. (2004), Cities Transformed: Demographic Change and its Implications in the Developing World, Londres, Earthscan. 
Orellana, A. (2002), El desafí de las áreas metropolitanas en un mundo globalizado. Una mirada a Europa y América Latina, Barcelona, Instituto Catalán de Cooperación Iberoamericana/Instituto de Estudio Territoriales de la Universidad Pompeu Fabra/ Instituto de Estudios Urbanos de la Pontifica Universidad Católica de Chile (RIDEAL).

Pinto da Cunha, M. (2002), Urbanización, territorio y cambios socioeconómicos estructurales en América Latina y el Caribe, Santiago de Chile, CEPAL (Población y Desarrollo, 30).

Portes, A. (2001), "Inmigración y metrópolis: reflexiones acerca de la historia urbana”, Migraciones Internacionales, vol. 1, núm. 1, pp. 111-134.

Preteceille, E. (1994), “Cidades globais e segmentação social”, en L. C. Queiroz Ribeiro y O. Santos Jr. (coords.), Globalização, fragmentação e reforma urbana: o futuro das cidades na crise, Río de Janeiro, Civilização Brasileira, pp. 65-92.

Ribeiro, L. y L. Lago (1999), "O espaço social das grandes metrópoles brasileiras: Rio de Janeiro, São Paulo e Belo Horizonte”, Observatório de Políticas Urbanas e Gestão Municipal (IPPUR/UFrJ-FASE). Disponible en: http://www.ippur.ufrj.br/observatorio/download/espaco_social_metropoles. pdf.

Rodríguez, Alfredo y Lucy Winchester (2001), "Santiago de Chile: metropolización, globalización, desigualdad”, Eure, Revists Latinoamericana de Estudios Urbano Regionales, vol. 27, núm. 80, pp.121-139.

Rodríguez, J. (2005), "Reproducción en la adolescencia: el caso de Chile y sus implicaciones de política”, Revista de la CEPAL, núm. 86, pp. 123-146 (LC/ G.2282-P/E).

(2004), Migración interna en América Latina y el Caribe: estudio regional del periodo 1980-2000, CEPAL (Población y Desarrollo, 50).

(2002), Distribución espacial de la población de América Latina y el Caribe: tendencias, interpretaciones y desafíos para las políticas públicas, Santiago, CEPAL (Población y Desarrollo, 32).

- (2001), Segregación residencial socioeconómica: ¿qué es?, ¿cómo se mide?, ¿qué está pasando?, ¿importa?, Santiago de Chile, CEPAL (Población y Desarrollo, 16).

- (1993), "Evolución de la población del Gran Santiago: tendencias, perspectivas y consecuencias”, Notas de Población, núm. 58, Celade.

Rodríguez, J. y C. Arriagada (2004), "Segregación residencial en la ciudad latinoamericana", Eure, Revista Latinoamericana de Estudios Urbano Regionales, vol. 30, núm. 89, pp. 5-24.

Rodríguez, J. y M. Villa (1996), “Demographic Trends in Latin America’s Metropolises, 1950-1990", en Gilbert Alan (ed.), The Mega-City in Latin America, Japón, United Nations University Press, pp. 25-52.

Sabatini, F., G. Cáceres y J. Cerda (2001), "Segregación residencial en las principales ciudades chilenas: tendencias de las tres últimas décadas y posibles cursos de acción”, Eure, Revista Latinoamericana de Estudios Urbanos Regionales, vol. 27, núm. 82, pp. 21-42. 
Sassen, S. (1991), The Global City, Princeton, Princeton University Press.

Schelling, T. (1978), Micromotives and Macrobehavior, Nueva York, Norton.

Schütz, E. (1996), Ciudades en América Latina: desarrollo barrial y vivienda, Santiago, Centro de Estudios Sociales y Educación/Ediciones SUR.

Silva, I. (2003), Disparidades, competitividad territorial y desarrollo local y regional en América Latina. Santiago, ILPES/CEPAL (Gestión Pública, 33).

Tilly, Ch. (1990), “Transplanted Networks”, en Virginia Yans-McLaughlin (ed.), Immigration Reconsidered: History, Sociology and Politics, Nueva York, Oxford University Press, pp. 79-95.

Wessel, T. (2000), "Social Polarization and Socioeconomic Segregation in a Welfare State: The Case of Oslo”, Urban Studies, vol. 30, núm. 11, pp. 19471967. 